\title{
Unliganded progesterone receptor- mediated targeting of an RNA-containing repressive complex silences a subset of hormone-inducible genes
}

\author{
Guillermo Pablo Vicent, ${ }^{1,2,3}$ A. Silvina Nacht, ${ }^{1,2}$ Roser Zaurin, ${ }^{1,2}$ Jofre Font-Mateu, ${ }^{1,2}$ \\ Daniel Soronellas, ${ }^{1,2}$ Francois Le Dily, ${ }^{1,2}$ Diana Reyes, ${ }^{1,2}$ and Miguel Beato ${ }^{1,2}$ \\ ${ }^{1}$ Centre for Genomic Regulation (CRG), E-08003 Barcelona, Spain; ${ }^{2}$ Universitat Pompeu Fabra (UPF), E-08003 Barcelona, Spain
}

\begin{abstract}
A close chromatin conformation precludes gene expression in eukaryotic cells. Genes activated by external cues have to overcome this repressive state by locally changing chromatin structure to a more open state. Although much is known about hormonal gene activation, how basal repression of regulated genes is targeted to the correct sites throughout the genome is not well understood. Here we report that in breast cancer cells, the unliganded progesterone receptor (PR) binds genomic sites and targets a repressive complex containing HP1 $\gamma$ (heterochromatin protein 1 $\gamma$ ), LSD1 (lysine-specific demethylase 1), HDAC1/2, CoREST (corepressor for REST [RE1 \{neuronal repressor element 1\} silencing transcription factor]), KDM5B, and the RNA SRA (steroid receptor RNA activator) to $20 \%$ of hormone-inducible genes, keeping these genes silenced prior to hormone treatment. The complex is anchored via binding of HP1 $\gamma$ to H3K9me3 (histone H3 tails trimethylated on Lys 9). SRA interacts with PR, HP1 $\gamma$, and LSD1, and its depletion compromises the loading of the repressive complex to target chromatinpromoting aberrant gene derepression. Upon hormonal treatment, the HP1 $\gamma$-LSD1 complex is displaced from these constitutively poorly expressed genes as a result of rapid phosphorylation of histone $\mathrm{H} 3$ at Ser 10 mediated by MSK1, which is recruited to the target sites by the activated PR. Displacement of the repressive complex enables the loading of coactivators needed for chromatin remodeling and activation of this set of genes, including genes involved in apoptosis and cell proliferation. These results highlight the importance of the unliganded PR in hormonal regulation of breast cancer cells.
\end{abstract}

[Keywords: basal repression; RNA-containing repressive complex; unliganded receptor; cell proliferation; progesterone gene regulation]

Supplemental material is available for this article.

Received February 1, 2013; revised version accepted April 22, 2013.

Eukaryotic DNA is packaged into chromatin, a nucleoprotein complex in which the fundamental repeating unit is the nucleosome, consisting of a core particle with 147 base pairs (bp) of DNA wrapped around an octamer of the core histones $\mathrm{H} 3, \mathrm{H} 4, \mathrm{H} 2 \mathrm{~A}$, and $\mathrm{H} 2 \mathrm{~B}$ (Luger et al. 1997) and a H1 linker histone protecting an additional 20-30 DNA base pairs. Nucleosomes are folded into a chromatin fiber exhibiting various levels of compaction due to interactions among core particles and among linker histones. Silenced genes are often maintained in a highly compacted chromatin that precludes access to regulatory information encoded in the DNA sequence. Access to this information in the context of gene regulation implies mechanisms that facilitate interaction of

${ }^{3}$ Corresponding author

E-mail guillermo.vicent@crg.es

Article is online at http://www.genesdev.org/cgi/doi/10.1101/gad.215293.113. transcription factors with their DNA target sequences in chromatin. Post-translational modification of histones is one mechanism to control DNA accessibility and plays fundamental roles in most biological processes that involve manipulation and expression of DNA (Bannister and Kouzarides 2011). Histone modifications, including acetylation, phosphorylation, methylation, ubiquitylation, sumolyation, and ADP-ribosylation, can act in combinations (Jenuwein and Allis 2001). The various combinations of chromatin marks at promoters and enhancers are recognized by subunits of protein complexes that contain the enzymatic activities needed for organizing the chromatin in an open/active or, rather, a closed/repressed conformation (Kouzarides 2007).

Heterochromatin protein 1 (HP1) is a conserved family of chromosomal proteins that participate in chromatin packaging and gene silencing. A loss of HP1 leads to lethality in Drosophila, and a decrease of HP1 correlates 
with metastasis in human breast cancer cells (Kirschmann et al. 2000; Lu et al. 2000). The chromodomain of HP1 proteins can associate with histone $\mathrm{H} 3$ tails trimethylated on Lys 9 (H3K9me3) (Bannister et al. 2001; Lachner et al. 2001) in a well-characterized process (Jacobs et al. 2001; Lachner et al. 2001; Nielsen et al. 2002). In mammals, HP1 is found in three forms: $\alpha, \beta$, and $\gamma$. All HP1s interact with methylated $\mathrm{H} 3 \mathrm{~K} 9$, but while $\mathrm{HP} 1 \alpha$ and $\mathrm{HP} 1 \beta$ are found in heterochromatin and silent regions of euchromatin, HP1 $\gamma$ also interacts with genes that can be actively transcribed (Lachner et al. 2001; Eissenberg and Shilatifard 2006). How HP1 $\gamma$ discriminates between H3K9me3 on repressed genes and on potentially active genes and how it exerts its repressive role are not yet clear.

The lysine-specific demethylase 1 (LSD1) specifically demethylates mono- or dimethyl groups on H3K4 (Shi et al. 2004, 2005) and is associated with gene repression through interaction with the corepressor for REST (RE1 [neuronal repressor element 1] silencing transcription factor [CoREST] and HDAC1/2 as part of a multiprotein complex [hereafter referred to as LSD1.com]) (Shi et al. 2005). LSD1 is essential for mammalian development and is involved in many biological processes (Wang et al. 2007). LSD1 also interacts with androgen receptor (AR) and acts as a coactivator for transcriptional induction by removal of a dimethyl group from H3K9 (Metzger et al. 2005). Either knockdown or pharmacological inhibition of LSD1 results in growth inhibition of breast cancer cells by affecting several proliferation-associated genes like p21, Erbb2, and Ccna2, thus making LSD1 an attractive target for treatment of estrogen receptor (ER)-negative breast cancers (Lim et al. 2010).

Nuclear receptors regulate gene expression in response to hormones by activating kinase signaling pathways that target chromatin and by recruiting to their binding sites on DNA coregulators that participate in modulating transcription (Lonard and O'Malley 2007). A wellcharacterized model system for studying these processes is the regulation of the expression of the mouse mammary tumor virus (MMTV). Promoter activity is induced by glucocorticoids, progestins, androgens, and, to a lesser extent, mineralocorticoids acting via several hormoneresponsive elements (HREs) (Hynes et al. 1983; Payvar et al. 1983; Scheidereit et al. 1983). The MMTV promoter is organized into positioned nucleosomes, with a nucleosome covering the HREs and the binding site for NF1 (Richard-Foy and Hager 1987; Truss et al. 1995). In cultured cells, full hormonal activation of the promoter requires not only the HREs, but also the adjacent NF1-binding site, indicating that both factors synergize in vivo (Chalepakis et al. 1988; Bruggemeier et al. 1990). Recent studies highlighted the complexity of enzymes that participate in chromatin opening during the first minutes of MMTV activation (Vicent et al. 2011; Beato and Vicent 2012; Wright et al. 2012). Progestin administration to T47D breast cancer cells activates the Src/Ras/Erk and CDK2 cascades, which are essential for progestin-induced cell proliferation (Migliaccio et al. 1998). Two consecutive cycles of chromatin remodeling catalyzed by at least 10 enzymes are needed to create the appropriate chromatin platform for transcription, leading to the displacement of the linker histone $\mathrm{H} 1$ and, subsequently, core histone H2A/H2B dimers (Beato and Vicent 2011).

One minute after hormone addition, activated progesterone receptor $(\mathrm{PR}), \mathrm{ERK}$, and MSK1 form a ternary complex, which is selectively recruited to the MMTV promoter nucleosome containing the HREs and promotes displacement of the HP1 $\gamma$ (Vicent et al. 2006). The chromodomain of HP1 needs an RNA-binding activity to gain appropriate nuclear localization (Maison et al. 2002; Muchardt et al. 2002). The LSD1.com complex also requires the $3^{\prime}$ domain of the noncoding RNA (ncRNA) HOTAIR to exert its repressive function at HOXD genes (Tsai et al. 2010). Moreover, the steroid receptor RNA activator (SRA) was proposed to stabilize the interaction of CTCF with cohesin at certain chromatin loci by binding both proteins simultaneously (Yao et al. 2010). The precise role of SRA in hormonal gene regulation is still a matter of debate (Colley and Leedman 2009, 2011).

In the present study, we address the mechanisms by which genes that are regulated by hormones are maintained in a silent state prior to hormone action. We found that the LSD1.com complex is used by the unliganded hormone receptors for maintaining gene silencing in the absence of hormones. The unliganded PR (uPR), the RNA SRA, and the HP1 $\gamma$ protein participate in the proper anchoring of the repressive complex to target sites in chromatin. Upon hormone induction, cross-talk with kinase signaling leads to local MSK1-dependent phosphorylation of histone $\mathrm{H} 3$, which facilitates removal of the repressive complex.

\section{Results}

HP1 $\gamma$ and the LSD1.com are found at the MMTV promoter prior to hormone treatment and are rapidly displaced upon hormone induction

We reported that $\mathrm{HP} 1 \gamma$ is displaced from the MMTV promoter 5-10 min after hormone induction /Vicent et al. 2006). As histone $\mathrm{H} 1$ displacement is already observed after $1 \mathrm{~min}$ of hormone induction (Vicent et al. 2011), we investigated the occupancy of HP1 $\gamma$ at earlier time points. Using T47D-MTVL cells carrying a single copy of the MMTV-luc transgene integrated in their genome (Truss et al. 1995), we found that HP1 $\gamma$ is evicted from the MMTV promoter after very short times of induction with the progestin analog R5020 (Fig. 1A). Already, after 1 min of hormone addition, $40 \%$ of HP1 $\gamma$ is displaced from the MMTV promoter, and after $5 \mathrm{~min},<40 \%$ of $\mathrm{HP} 1 \gamma$ remains bound. To identify potential partners that could be associated with HP1 $\gamma$ in the absence of hormone, we performed coimmunoprecipitation (co-IP) experiments using HP1 $\gamma$-specific antibodies. We found that HP1 $\gamma$ associates with components of the LSD1.com complex, including LSD1, HDAC1, CoREST, and BRAF35 (Fig. 1B, left panel; Hakimi et al. 2002; Shi et al. 2004; data not shown). In addition, we found in the immunoprecipitation 
A

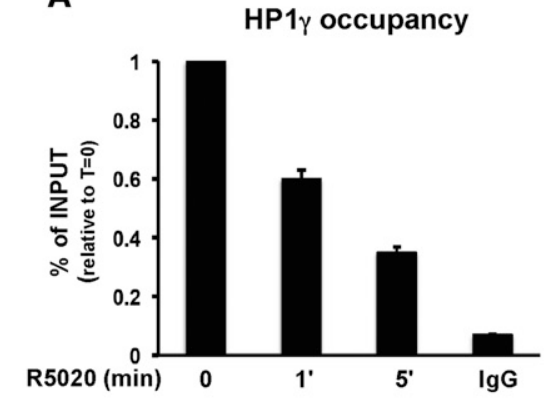

C
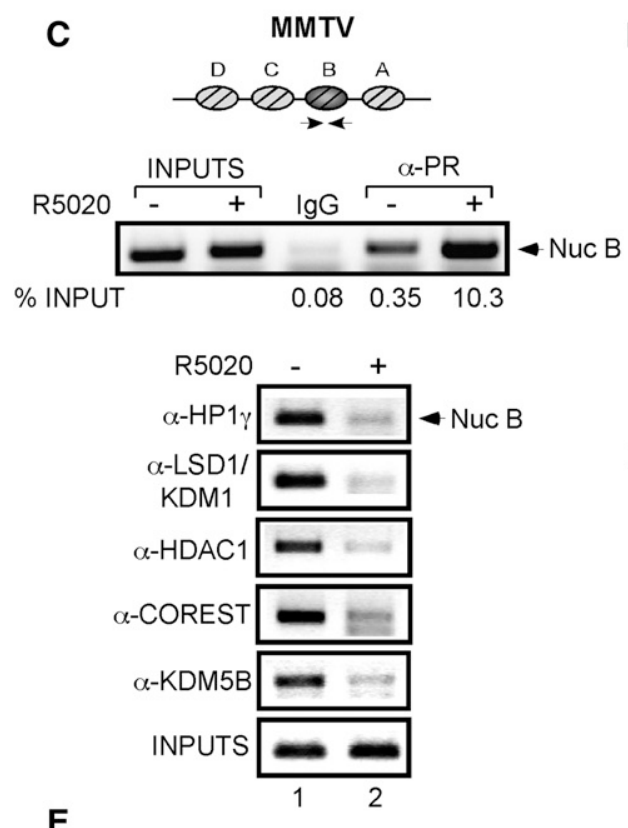

E

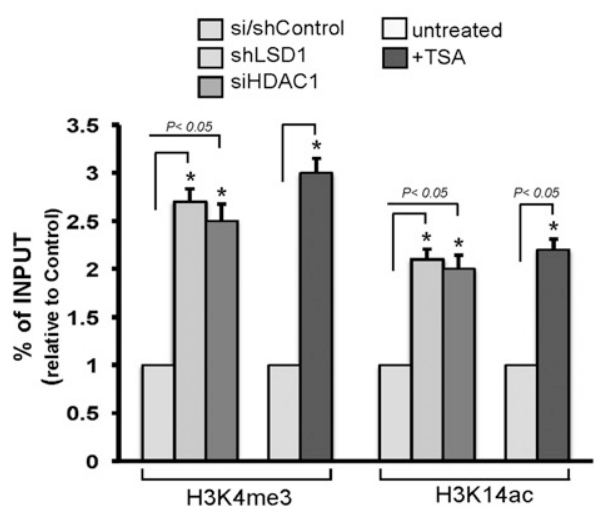

B

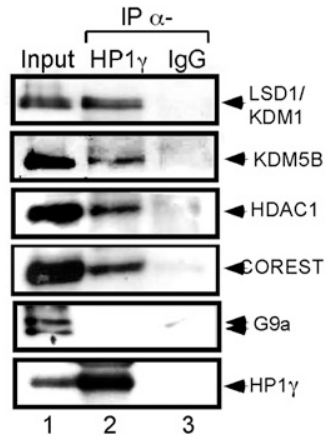

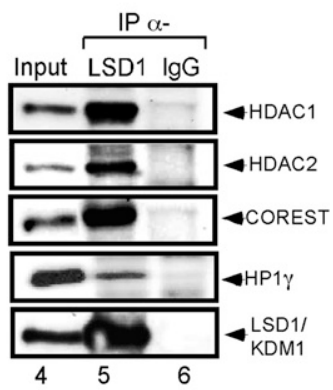

MMTV

D

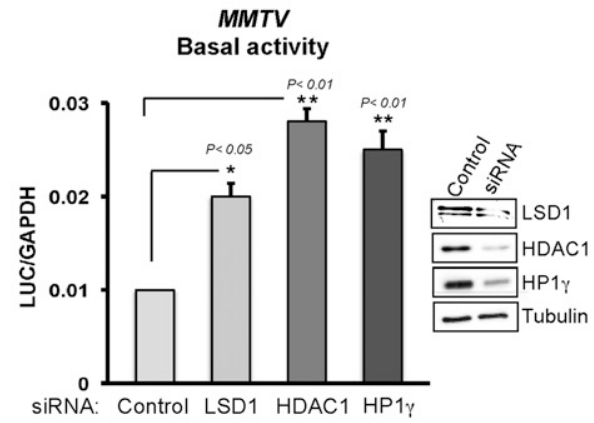

F
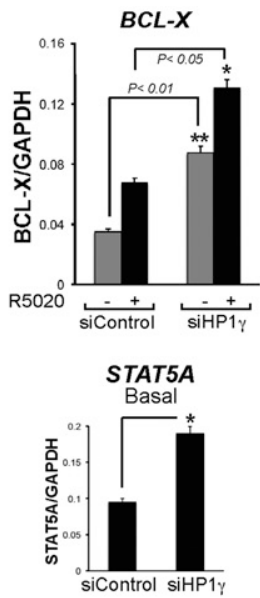

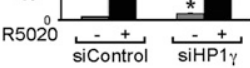

EGF

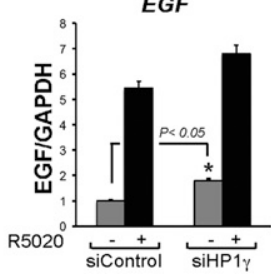

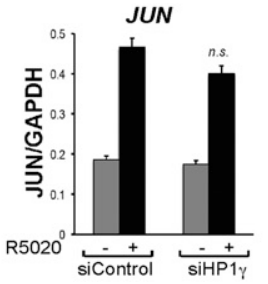

Figure 1. The LSD1.com complex is found at the MMTV promoter and is displaced after hormone induction. (A) T47D-MTVL cells were untreated $(0)$ or treated for 1 and 5 min with $10 \mathrm{nM}$ R5020 and subjected to ChIP assays with $\alpha$-HP1 $\gamma$-specific antibody. The precipitated DNA fragments were subjected to PCR analysis to test for the presence of sequences corresponding to the MMTV nucleosome B. A representative of three independent experiments is shown. (B) T47D-MTVL cells were lysed and immunoprecipitated with either $\alpha-\mathrm{HP} 1 \gamma$ - or LSD1-specific antibodies or normal mouse or rabbit IgG as a negative control for each immunoprecipitation (IgG). The immunoprecipitates (IP) were analyzed by Western blotting with LSD1-, KDM5B-, HDAC1-, HDAC2-, COREST-, G9a-, and HP1 $\gamma$-specific antibodies. (C) Cells were treated with R5020 for 5 min as indicated and subjected to ChIP assays with $\alpha$-HP1 $\gamma, \alpha$-LSD1, $\alpha$-HDAC1, $\alpha$-KDM5B, and $\alpha$-COREST. A representative of three independent experiments is shown. $(D)$ Cells were transfected with control siRNA or siRNA against either LSD1, HDAC1, or HP1 $\gamma$ as indicated, and the levels of these proteins were determined by Western blotting. (Left panel) Cells maintained $1 \mathrm{~d}$ in serum-free conditions were incubated with $10 \mathrm{nM}$ R5020 for 6 h, total RNA was prepared, and cDNA was generated and used as template for real-time PCR with luciferase oligonucleotides. The values represent the mean and standard deviation (SD) from three experiments performed in duplicate. $\left({ }^{\star}\right) P$-value $<0.05 ;\left({ }^{\star \star}\right) P$-value $<0.01$. $(E)$ Cells were transfected with either control, LSD1-specific, or HDAC1-specific siRNAs and subjected to ChIP assays with $\alpha-\mathrm{H} 3 \mathrm{~K} 4 \mathrm{me} 3$ and $\alpha-\mathrm{H} 3 \mathrm{~K} 14 \mathrm{ac}$. Cells were also treated or not with TSA and subjected to ChIP assays. The histograms show the mean \pm SD of three experiments performed in duplicate. $\left(^{\star}\right) P$-value $<0.05 .(F)$ cDNA was generated from cells transfected with control and HP1 $\gamma$ siRNAs and used as template for real-time PCR with gene-specific primers. The values were normalized with GAPDH. The histograms show the mean $\pm \mathrm{SD}$ of three experiments performed in duplicate. $\left({ }^{\star}\right) P$-value $<0.05 ;\left({ }^{\star \star}\right) P$-value $<0.01$. 
the protein REST and the JARID1B/KDM5B/PLU-1, an H3K4-specific histone demethylase highly expressed in breast cancer cells (Lu et al. 1999; Barrett et al. 2002; Yamane et al. 2007) and previously shown to be associated to progestin target sites (Supplemental Fig. S1A and Fig. 1B, respectively; Vicent et al. 2011). The K9 methyltransferase G9a, identified previously as a CoREST interactor (Ooi and Wood 2007), and the SLIRP protein (Hatchell et al. 2006) were not found to be associated with HP1 $\gamma$ in T47D-MTVL cells (Fig. 1 B; Supplemental Fig. S1A). An immunoprecipitation using a LSD1 antibody confirmed the known interaction of LSD1 with the HDAC1, HDAC2, and CoREST as well as with the new interactor HP1 $\gamma$ (Fig. 1B, right panel). Chromatin immunoprecipitation (ChIP) experiments performed in the absence and presence of the hormone for 5 min showed displacement of HP1 $\gamma$ protein from the MMTV promoter along with KDM5B and components of LSD1.com (Fig. 1C). Interestingly, in the absence of hormone, we detected binding of PR to the MMTV promoter (Fig. 1C, top panel). Hence, HP1 $\gamma$ associated with LSD1.com (HP1 $\gamma$-LSD1 complex) is bound to the MMTV promoter in the absence of hormone and rapidly leaves the promoter after induction.

To check whether HP1 $\gamma$ can directly interact with LSD1, we performed co-IP experiments using recombinant proteins. Immunoprecipitation of LSD1 brought down HP1 $\gamma$, while the mock precipitation with control IgG did not (Supplemental Fig. S1B). The reverse experiment using a HP1 $\gamma$ antibody for the immunoprecipitation and a LSD1 antibody for blotting confirmed a direct interaction between the demethylase LSD1 and HP1 $\gamma$ protein (Supplemental Fig. S1B). These results are in line with recent studies showing that a ternary complex composed of HP1 $\alpha$, LSD1, and ASXL1 (additional sex comblike 1) is involved in retinoic acid-dependent repression (Lee et al. 2010), although, to our knowledge, this is the first report of an association of the LSD1.com complex with HP1 $\gamma$.

The HP1 $\gamma-L S D 1$ complex represses the basal activity of hormone-induced genes

To find out whether the HP1 $\gamma$-LSD1 complex is important for the basal activity of the MMTV promoter prior to hormone treatment, we performed transcriptional assays in cells transiently depleted of HP1 $\gamma$ and LSD1. First, we confirmed by ChIP that depletion by siRNA knockdown of HDAC1, LSD1, and HP1 $\gamma$ led to a decrease of each protein found at the MMTV promoter in the absence of hormone (Supplemental Fig. S2). Compared with control cells transfected with scramble siRNAs, the basal activity of the MMTV promoter increases at least twofold after depletion of LSD1, HDAC1, or HP1 $\gamma$ (Fig. 1D), suggesting that the HP1 $\gamma$-LSD1 complex fulfills a repressive function prior to hormone treatment.

We showed that after hormone induction, the MMTV promoter exhibits higher levels of H3K4me3 and H3K14ac (Vicent et al. 2006, 2011). We found that knockdown of LSD1 increased H3K4me3 level, while knockdown of
HDAC1 increased H3K14ac level at the MMTV promoter prior to hormone induction (Fig. 1E), suggesting that the HP1 $\gamma$-LSD1 complex contributes to maintaining low levels of these histone marks. To test whether methylation and acetylation are linked, we measured the levels of H3K4me3 and H3K14ac in cells either depleted of LSD1 or treated with the HDAC inhibitor TSA. Our results showed that in the absence of LSD1, the levels of H3K14ac in the MMTV promoter increased along with H3K4me3. Similarly, inhibition of HDACs increased acetylation concomitantly with H3K4me3 (Fig. 1E). Thus, histone deacetylation and demethylation are linked and mediated by activities present in the HP1 $\gamma$-LSD1 complex, confirming previous work (Lee et al. 2006). H3K4me3 and H3K14ac signals were reported to be critical for binding of the ATP-dependent chromatin remodeling complexes hNURF and BAF, respectively, to PR target promoters (Vicent et al. 2009, 2011).

Basal transcriptional activity of three endogenous progesterone target genes-BCL-X, STAT5A, and EGF-was increased by HPl $\gamma$ depletion to a level similar or superior to that observed for MMTV-Luc (Fig. 1F). Moreover, progestin induction of MMTV, BCL-X, and STAT5A was affected by the HP1 $\gamma$ siRNAs, which did not inhibit progestin induction of the Jun gene (Fig. 1F), thus excluding a general effect on PR function. In the absence of the HP1 $\gamma$-LSD1.com complex, the target chromatin exhibited an increase in the active epigenetic marks H3K14ac and H3K4me3 (Fig. 1E), which facilitated PR-dependent activation (Fig. 1F). We conclude that low basal transcriptional as well as optimal induction of several, but not all, progesterone target genes depend on the physiological levels of HP1 $\gamma$. In these genes, the HP1 $\gamma$-containing repressive complex represses the basal activity and is evicted upon hormone induction.

The H3S10phos mark generated by progesteroneactivated MSK1 is critical for HP1 $\gamma-L S D 1$ complex eviction

After hormone addition, the kinase MSK1 is recruited to progesterone target genes along with the PR and the activated kinase ERK1/2 (Vicent et al. 2006). Once at the promoter, activated MSK1 phosphorylates histone H3 at Ser 10, favoring the displacement of the HP1 $\gamma$ by a methyl/phospho switch mechanism (Fischle et al. 2005; Vicent et al. 2006). We thus asked whether displacement of the whole HP1 $\gamma$-LSD1 complex from target chromatin is dependent on MSK1 activity and analyzed the displacement at a very short time after adding hormone. Recruitment of MSK1 to the MMTV promoter was already maximal after $1 \mathrm{~min}$ of hormone treatment and was accompanied by a marked decrease of HP1 $\gamma$ and LSD1 (Fig. 2A) and a parallel increase in H3S10ph (Supplemental Fig. S3A). To demonstrate that the displacement of HP1 $\gamma$-LSD1 required MSK1 activity, we took advantage of the MSK1 inhibitor H89, which had been previously shown to inhibit hormone-dependent activation of the MMTV promoter and other progestin-regulated genes (Vicent et al. 2006). Incubation of T47D-MTVL 


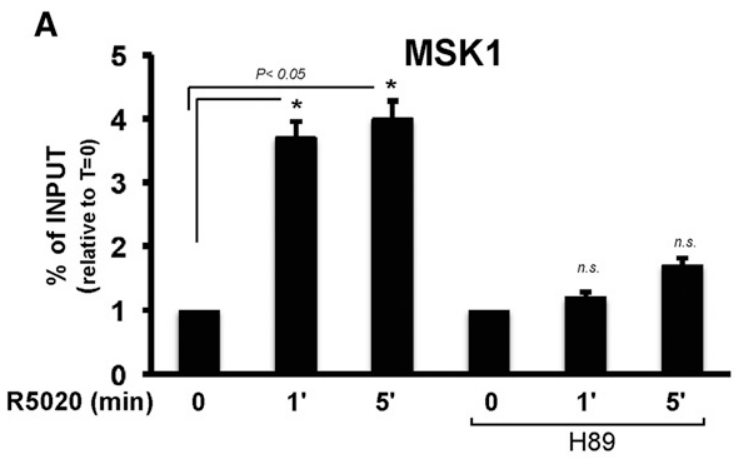

B
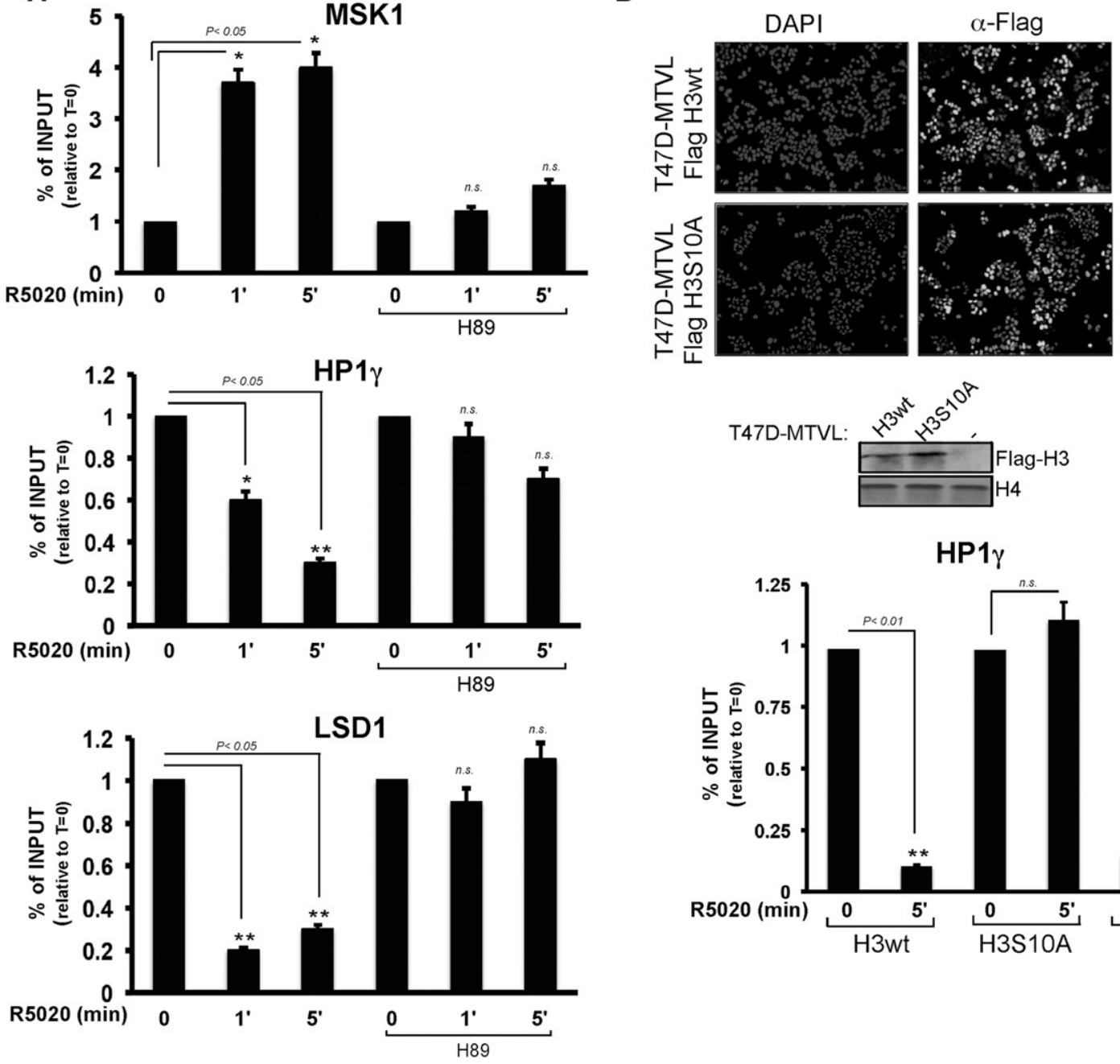

C

\section{LSD1}

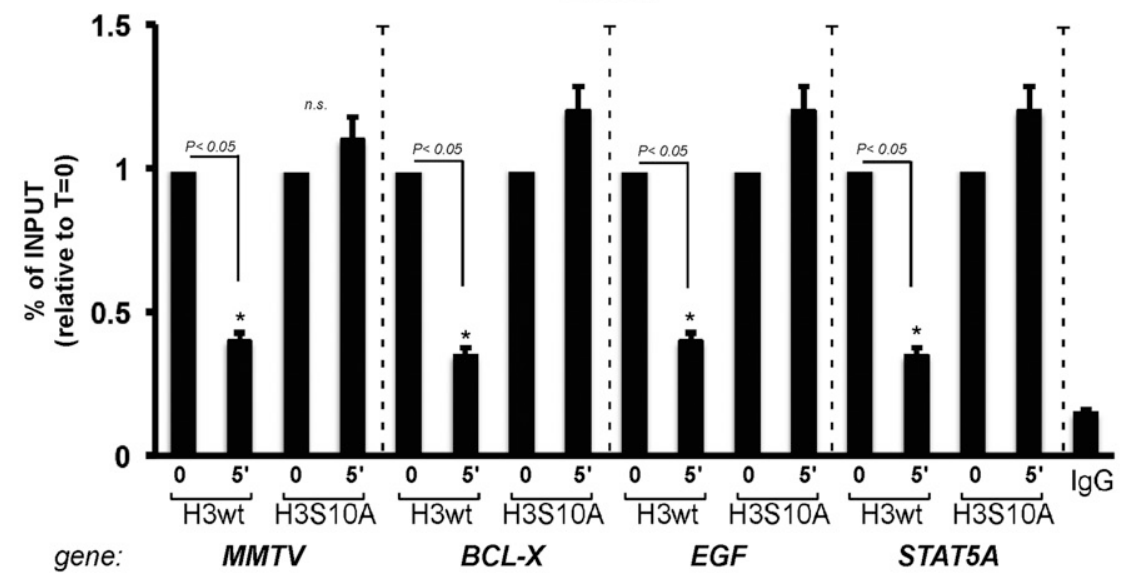

Figure 2. The H3S10phos mark is critical for HP1 $\gamma$-LSD1.com complex eviction. (A) T47D-MTVL control cells and cells treated with the Msk inhibitor H89 were incubated with hormone and submitted to ChIP assays with antibodies to MSK1, HP1 $\gamma$, or LSD1. ( ${ }^{\star}$ ) $P$-value $\left.<0.05 ;{ }^{\star \star}\right) P$-value $<0.01$. $(B$, top panel) T47D-MTVL cells stably expressing wild-type Flag-H3 or the mutant Flag-H3S10A were fixed and immunostained with $\alpha$-Flag or DAPI. (Middle panel) The levels of Flag-H3 were monitored by Western blot. (Bottom panel) Wild-type Flag-H3 or the mutant Flag-H3S10A cells were treated with hormone for the indicated times and subjected to ChIP assays with $\alpha$-HP1 $\gamma$ antibody or control IgG. $\left.{ }^{\star \star}\right) P$-value $<0.01 .(C)$ Flag-H3 and Flag-H3S10A cells were treated with hormone for 5 min and subjected to ChIP assays with $\alpha$-LSD1 antibody or control IgG. $\left(^{\star}\right) P$-value $<0.05$. 
cells with H89 prior to hormone addition decreased the recruitment of MSK1 to the MMTV promoter as measured by ChIP (Fig. 2A, top panel). Concomitantly, H3S10ph as well as the displacement of both HP1 $\gamma$ and LSD1 from the MMTV promoter were severely affected by the H89 inhibitor (Fig. 2A, middle and bottom panels, respectively; Supplemental Fig. S3A). Similar results were obtained in MSK1-depleted cells (Vicent et al. 2006; data not shown). Thus, the kinase activity of MSK1 is required for the displacement of the HP1 $\gamma$-LSD1 complex that occurs already $1 \mathrm{~min}$ after hormone addition.

To address the relevance of the H3S10phos mark for the displacement of the HP1 $\gamma$-LSD1 complex, we performed ChIP experiments in T47D-MTVL cell lines stably expressing wild-type flagged histone $\mathrm{H} 3$ or a mutant version (H3S10A), both expressed at similar levels and localized to the cell nucleus (Fig. 2B). In cells expressing wild-type $\mathrm{H} 3$, displacement of HP1 $\gamma$ from the MMTV promoter is observed after 5 min of hormone induction, while HP1 $\gamma$ eviction is compromised in cells expressing the H3S10A mutant (Fig. 2B, bottom panel). We also tested hormone-dependent LSD1 displacement in endogenous progesterone target genes. ChIP experiments using LSD1-specific antibodies in H3wt and H3S10A cell lines showed H3S10 phosphorylation dependence for LSD1 eviction in the MMTV transgene and three endogenous genes (BCL-X,EGF, and STAT5A) (Fig. 2C), which have been previously shown to be affected by $\mathrm{HP} 1 \gamma$ protein levels (Fig. 1F). Previous reports showed that H3S10phos as well as H3K14ac are directly involved in HP1 eviction (Mateescu et al. 2004; Fischle et al. 2005). Thus, pull-down experiments with T47D-MTVL nuclear extracts and biotinylated peptides of the $\mathrm{H} 3$ tail containing various modifications were used to test whether H3S10 phosphorylation and K14 acetylation influence $\mathrm{HP} 1 \gamma-$ LSD1.com binding. We detected binding of HP1 $\gamma$ and LSD1 to histone tails containing H3K9me3 (Supplemental Fig. S3B, cf. lanes 1 and 2), which was reduced by the addition of S10phos either alone or in combination with K14ac (Supplemental Fig. S3B, cf. lanes 2 and 3,4). Similar results were obtained when recombinant HP1 $\gamma$ was used instead of nuclear extracts (Supplemental Fig. S3B, right panel), speaking for a direct interaction. Thus, the H3S10ph mark deposited by activated MSK1 is critical for the displacement of the HP1 $\gamma$-LSD1 complex and subsequent transcriptional activation.

\section{uPR targets the HP1 $\gamma-L S D 1$ complex to PR-binding} sites (PRbs) in chromatin

Since HP1 proteins can bind the H3K9me3 mark, which is present in the MMTV promoter prior to hormone treatment (Vicent et al. 2006), we hypothesized that this could be a targeting mechanism for HP1 $\gamma$-LSD1.com. To test this hypothesis, we performed ChIP experiments around PRbs in hormone-untreated T47D-MTVL cells using specific antibodies against LSD1, HP1 $\gamma, \mathrm{PR}$, and H3K9me3. We found that the repressive complex is restricted to the PRbs in the MMTV transgene as well as in the endogenous progesterone target gene STAT5A, coinciding with the binding of uPR (Fig. 3A). By sequential ChIP (re-ChIP), we found that PR and HP1 $\gamma$ bind simultaneously to the same DNA region in the $M M T V$, STAT5A, and BCL-X PRbs (Fig. 3B). In contrast, the H3K9me3 signal was not preferentially localized at the PRbs and exhibited a more widespread distribution (Fig. 3A). Similar results were found for EGF, another progesterone target gene (data not shown). Genomewide analysis of $\mathrm{H} 3 \mathrm{~K} 9 \mathrm{me} 3$ by ChIP combined with deep sequencing (ChIP-seq) showed an overlap with HP1 $\gamma$ and LSD1 (see Fig. 6A, below), but there are many more $\mathrm{H} 3 \mathrm{~K} 9 \mathrm{me} 3$ regions than $\mathrm{HP} 1 \gamma$ - and LSD1-binding sites.. Thus, the genomic targeting of the HP1 $\gamma$-LSD1 complex could not be explained only by the presence of the H3K9me3 mark, and other factors must be involved.

To address this point, we first analyzed the role of the uPR in HP1 $\gamma$-LSD1 complex targeting. We used co-IP to test whether the HP1 $\gamma$-LSD1 complex interacts with PR in T47D-MTVL cells. We found that an antibody to PR precipitates LSD1, HDAC1, and $\mathrm{HP} 1 \gamma$ in the absence of hormone as well as $30 \mathrm{~min}$ after hormone addition (Fig. 3C), in agreement with the colocalization of uPR and the HP1 $\gamma$-LSD1 complex at PRbs (Fig. 3A,B). In contrast, the interaction of $\mathrm{PR}$ with the coactivator SRC1 was hormone-dependent (Fig. 3C, left panel). The uPR interaction with the repressive complex was confirmed by the reverse co-IP experiment using an $\mathrm{HP} 1 \gamma$-specific antibody (Fig. 3C, right panel). Incubation of recombinant PR with recombinant $\mathrm{HP} 1 \gamma$ followed by immunoprecipitation with a PR-specific antibody yielded a precipitate containing the HP1 $\gamma$ protein, absent from the IgG control (Supplemental Fig. S4A, lane 2 vs. lane 3). Thus, the interaction between the repressive complex and PR observed in cell extracts could be mediated by a direct binding of PR to the HP1 $\gamma$ protein.

Co-IP experiments performed in T47D cells expressing either $\mathrm{PR}_{\mathrm{A}}$ or $\mathrm{PR}_{\mathrm{B}}$ showed stronger interaction of the HP1 $\gamma$-LSD1 complex with $\mathrm{PR}_{\mathrm{B}}$ compared with $\mathrm{PR}_{\mathrm{A}}$ (Supplemental Fig. S4B, cf. lanes 5 and 4,6,7). Thus, the 164 amino acids present only in $\mathrm{PR}_{\mathrm{B}}$ stabilized binding to the HP1 $\gamma$-LSD1-repressive complex, which also interacts with other regions of PR. As a control, we performed the same co-IPs using extracts from T47DY cells that express low levels of both PR isoforms and found no significant signal (Supplemental Fig. S4B, lane 6; Horwitz et al. 1995).

To examine whether PR is required for genomic targeting of the HP1 $\gamma$-LSD1 complex, we performed co-IP experiments in wild-type T47D MTVL and T47DY cells. First, we found that the interaction between HP1 $\gamma$ and LSD1.com is observed independently of the presence of PR (Supplemental Fig. S4C, cf. lanes 2 and 3). In ChIP assays, the decrease on PR binding to PRbs observed in T47DY cells compared with wild-type cells is accompanied by a decrease in LSD1 binding in the progesterone target genes STAT5A, BIRC3, and DUSP1 (Fig. 3D). The reduction in the presence of LSD1 in T47DY cells is translated in an increase in the basal activity of those genes (Fig. 3E). Similar results were obtained in cells depleted of PR by siRNA knockdown when STAT5A, $B C L-X$, and $E G F$ genes were tested (data not shown). 
A
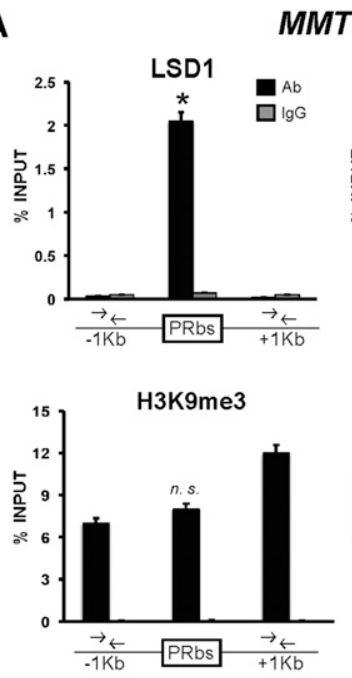

B

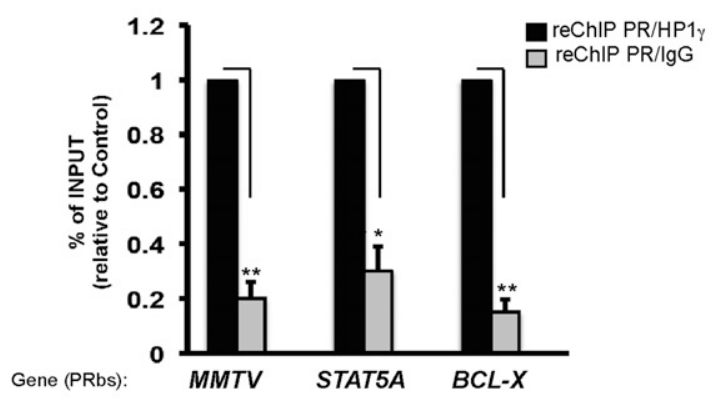

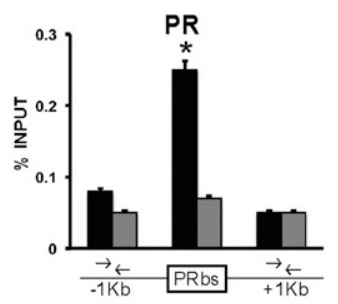

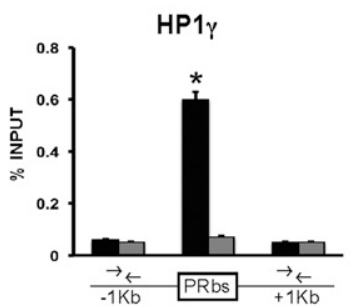

C

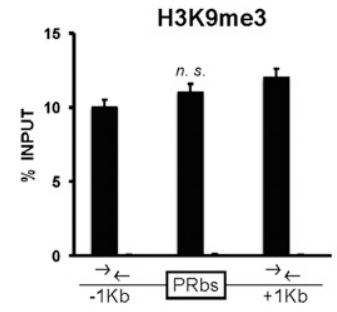

STAT5A
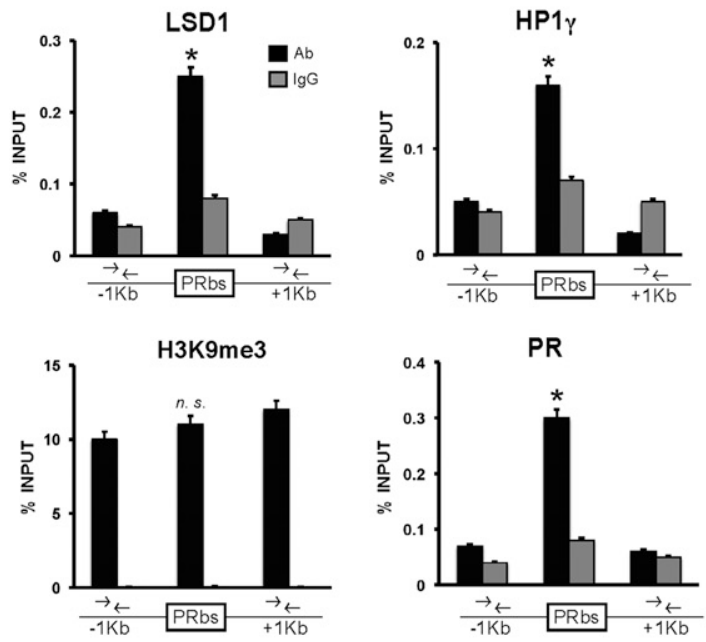

D
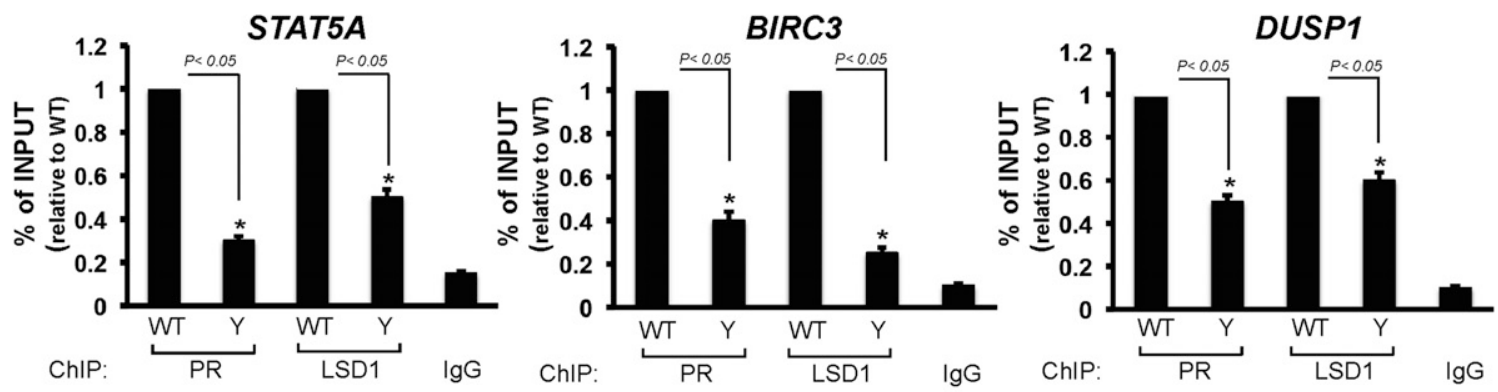

E

STAT5A

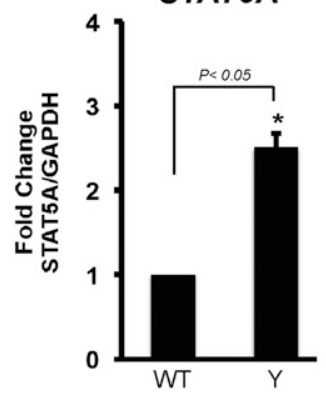

BIRC3
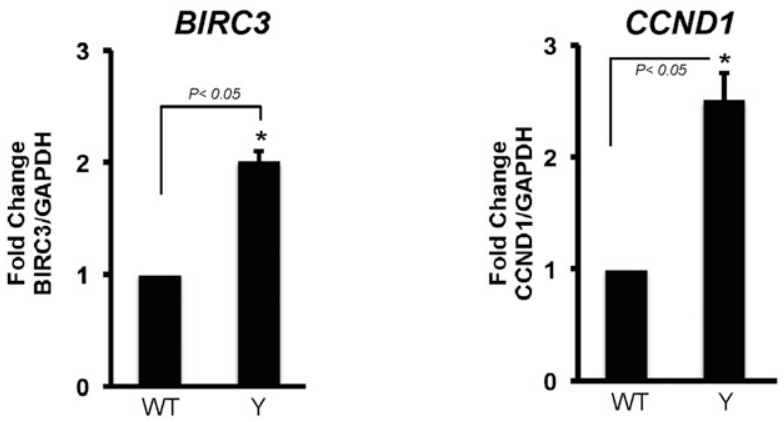

Figure 3. The uPR is important for HP1 $\gamma$-LSD1.com complex targeting to chromatin. (A) T47D-MTVL cells were subjected to ChIP assays with antibodies to HP1 $\gamma$, LSD1, H3K9me3, or PR. Precipitated DNA was analyzed by quantitative PCR for the presence of sequences corresponding to the MMTV nucleosome B or STAT5A PRbs as well as for regions located $\pm 1 \mathrm{~kb}$ away. $\left({ }^{\star}\right) P$-value $<0.05$. (B) Cells were subjected to re-ChIP assays with $\alpha$-PR (first immunoprecipitation) followed by $\alpha$-HP1 $\gamma$ or IgG for the second immunoprecipitation. Precipitated DNA was analyzed by PCR for the presence of sequences corresponding to nucleosome B, STAT5A, and $B C L-X .\left(^{\star}\right) P$-value $\left.<0.05 ;\left.\right|^{\star \star}\right) P$-value $<0.01 .(C)$ T47D-MTVL or T47DY $\left(\mathrm{PR}_{\mathrm{A}}{ }^{-} / \mathrm{PR}_{\mathrm{B}}{ }^{-}\right)$cells were lysed and immunoprecipitated with $\alpha$-HP1 $\gamma$-specific antibody or normal mouse IgG (IgG). The immunoprecipitates were analyzed by Western blotting with $\alpha$-LSD1, $\alpha$-HDAC1, and $\alpha$-HP1 $\gamma$ (top panel) or with $\alpha$-PR (bottom panel). (D) T47D-MTVL or T47DY cells were subjected to ChIP assays with antibodies to PR or LSD1. $\left(^{\star}\right) P$-value $<0.05$. (E) T47D-MTVL or T47DY cells were lysed, total RNA was prepared, and cDNA was generated and used as template for real-time PCR with specific primers for STAT5A, BIRC3, and CCND1 genes. The values were normalized with GAPDH and represent the mean and standard deviation from three experiments performed in duplicate. $\left(^{\star}\right) P$-value $<0.05$. 
Thus, the $\mathrm{uPR}$ is required for anchoring of the HP1 $\gamma$ LSD1 complex to PR target sites.

\section{The SRA RNA is involved in repressive complex anchoring to chromatin}

We next asked whether, besides uPR, other factors participate in anchoring the repressive complex to target chromatin sites. Several reports point to a possible role of RNA molecules in targeting distinct complexes to chromatin, and the chromodomain of HP1 proteins has been reported to interact with RNA (Akhtar et al. 2000; Maison et al. 2002; Muchardt et al. 2002; Huarte et al. 2010; Tsai et al. 2010; for review, see Wang and Chang 2011). To explore a possible role of an RNA, permeabilized T47D MTVL cells were treated with RNase A as previously described (Maison et al. 2002) and subjected to ChIP assays. RNase A treatment reduced the cellular RNA content to $<20 \%$ (Fig. 4A, inset) and promoted a significant displacement of both HP1 $\gamma$ and LSD1 from the MMTV transgene as well as from the BIRC3 and STAT5A genes (Fig. 4A). Thus, in addition to uPR, an RNA component could be required for the anchoring of the repressive complex to chromatin.

To identify the RNAs responsible for HP1 $\gamma$-LSD1 genomic anchoring, we tested various RNAs that have been reported to either be implicated in steroid hormone action (GAS5 and SRA) (Lanz et al. 1999; Kino et al. 2010) or act as scaffold of the LSD1.com complex (HOTAIR) (Tsai et al. 2010). T47D MTVL cells depleted of GAS5, SRA, and HOTAIR by specific siRNAs were treated with hormone, and the transcriptional induction of progesterone target genes was analyzed. Depletion of HOTAIR or GAS5 caused opposite effects on the basal and hormone-induced activity, which was gene-specific (Fig. 4B). In contrast, depletion of SRA consistently increased the basal and hormone-dependent activity of all tested genes, including MMTV, STAT5A, BCL-X, BIRC3, and EGFR, which have been shown to be dependent on the presence of the HP1 $\gamma$-LSD1 complex (Fig. 1F). In order to exclude any "off-target" effects of the siRNA, we validated the most relevant results using two siRNAs for SRA (Supplemental Fig. S5A). In all of these genes, hormone induction was significantly reduced upon depletion of SRA. Thus, although other ncRNAs may be involved in hormonal gene regulation of particular genes, we focused on the more general function of SRA, which correlates with the function of the HP1 $\gamma$-LSD1-repressive complex.

As SRA can be translated to yield the protein SRAP (Emberley et al. 2003), we asked whether SRA or SRAP are responsible for the observed effect in gene regulation. T47D-MTVL cells were transfected with different concentrations of an SRA construct that cannot be translated into the protein SRAP (Supplemental Fig. S6A; Lanz et al. 1999), and the basal activity of target genes was measured. In contrast to what was observed after SRA knockdown (Fig. 4B), the increase in SRA RNA produced $35 \%-50 \%$ reduction in the basal activity of $M M T V$, STAT5A, BCL-X, and BIRC3 genes (Supplemental Fig. $\mathrm{S} 6 \mathrm{~A}$, bottom panel). In addition, we performed rescue experiments in which the siRNA-mediated knockdown was recovered by the transfection of a resistant version of SRA that, in addition, does not code for SRAP. The increased basal activity observed in BIRC3 and STAT5A genes after SRA depletion returned to basal levels upon SRA mutant expression (Fig. 4C). Thus, depletion as well as overexpression of SRA RNA changed the basal activity of genes, which have been shown to be dependent on the HP1 $\gamma$-LSD1-repressive complex.

Next, we tested whether SRA or SRAP interact with the repressive complex. Whole-cell extracts from T47DMTVL cells were immunoprecipitated with anti-HP1 $\gamma$ antibody and separated into two fractions for RNA and Western blot analysis. As expected, SRAP was present in the extract, and members of the LSD1.com complex, such as LSD1 and HDAC1, precipitated with the HP1 $\gamma$ protein, but we could not detect SRAP in the HP1 $\gamma$ co-IP (Fig. 5A). RNAs extracted from the co-IP were treated with DNase I and subjected to RT-PCR, and the resulting cDNA was amplified with primers specific for SRA or GAPDH (negative control) (Hatchell et al. 2006). We found that SRA coimmunoprecipitated with $\mathrm{HP} 1 \gamma$ but not with IgG (Fig. 5A, bottom panel). Next, RNA immunoprecipitation (RIP) assays showed that SRA coimmunoprecipitated with LSD1 in the absence of hormone (Fig. 5B). Intriguingly, a hormone-dependent decrease in SRA-LSD1 interaction was observed (Fig. 5B), suggesting that SRA dissociates from part of the repressive complex after hormonal induction. Finally, RIP assays performed with PR-specific antibodies showed interaction of SRA with PR, which also diminished after hormone treatment (Supplemental Fig. S6B). To study whether LSD1, HP1 $\gamma$, or PR interact directly with SRA, we performed filterbinding assays with the recombinant proteins and in vitro synthesized radioactive SRA. We found a direct interaction of PR with SRA, while no significant interaction of HP1 $\gamma$ or LSD1 was detected in our experimental conditions (Supplemental Fig. S7A). Binding of PR with SRA was efficiently competed by 100-fold molar excess of the unlabeled SRA (Supplemental Fig. S7B). Importantly, competition experiments using an RNA encompassing the stem-loop structure 7 (STR7), a region of SRA previously shown to be critical for interaction with SHARP/SLIRP (Hatchell et al. 2006), showed 40\% decrease in binding (Supplemental Fig. S6B). Thus, as previously reported for its role as coactivator, SRA functional regions were not limited to a single discrete domain but likely require several regions (Leygue 2007).

Next, we analyzed whether the repressive complex is formed and can interact with UPR in the absence of the SRA. Co-IP experiments showed that the interaction of $\mathrm{UPR}$ with the repressive complex was affected by SRA knockdown (Supplemental Fig. S6C, cf. lanes 3 and 4). To test whether SRA depletion destabilized the binding of the repressive complex to target sites, ChIP experiments were performed in cells transfected with control and SRA siRNAs. We found a significant decrease in the levels of HP1 $\gamma$ and LSD1 bound to target chromatin regions of MMTV, BIRC3, BCL-X, DUSP1, and STAT5A genes when SRA levels were reduced (Fig. 5C, left panel; 


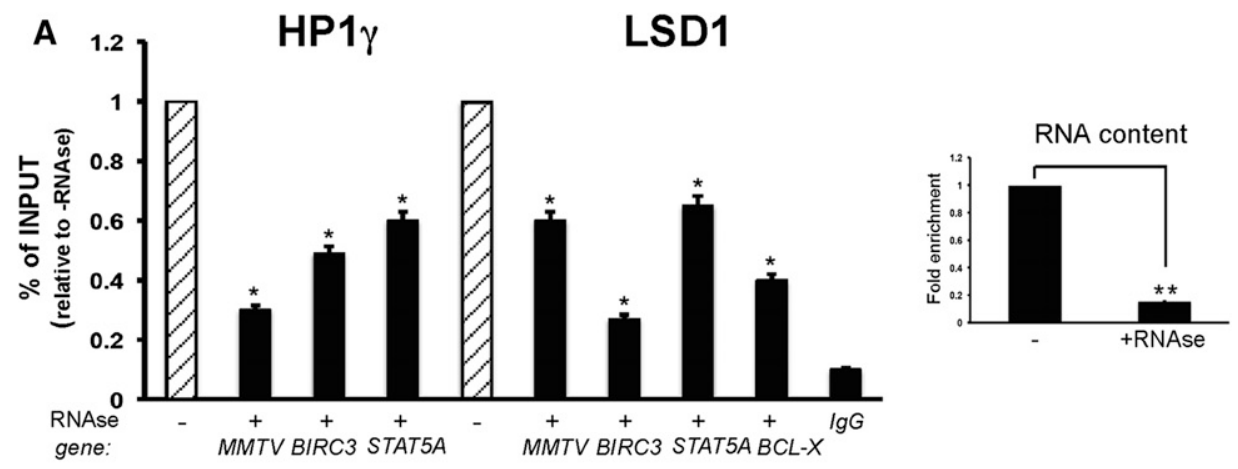

B
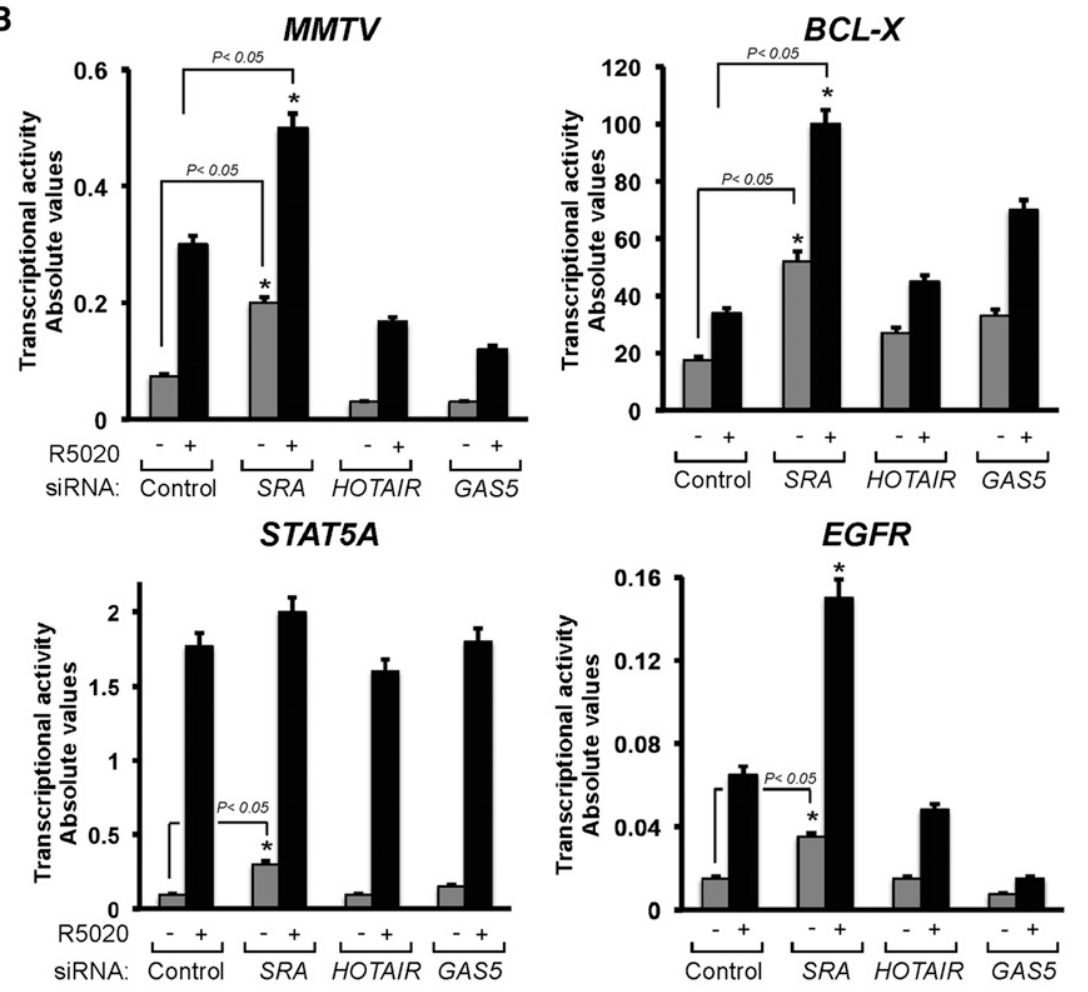

C

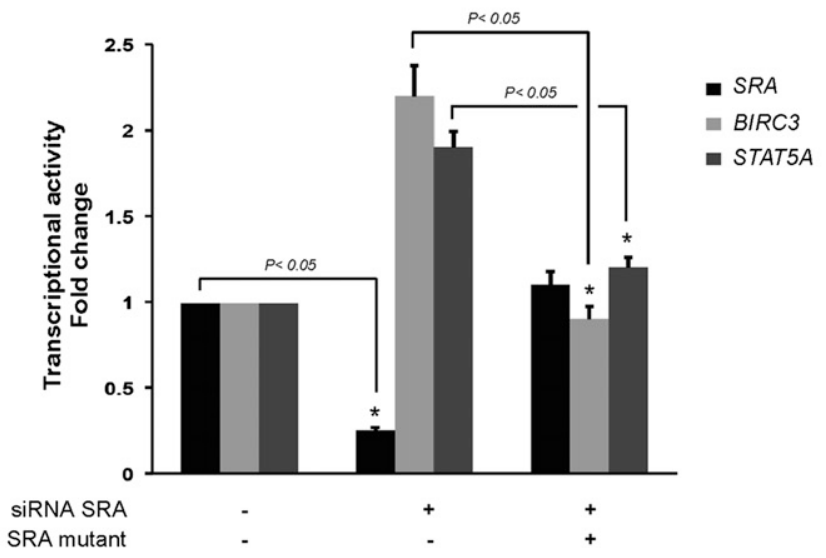

Figure 4. An RNA component is critical for anchoring of the HP1 $\gamma$-LSD1.com-repressive complex. (A) Permeabilized T47D-MTVL cells treated or not with RNase A were subjected to ChIP assays with antibodies to HP1 $\gamma$ and LSD1. Precipitated DNA was analyzed by quantitative PCR for the presence of sequences corresponding to the MMTV nucleosome $\mathrm{B}$, STAT5A, or BIRC3 PRbs. $\left.{ }^{\star}\right) P$-value $<$ 0.05. (Right panel) The RNA content before and after RNase treatment is also shown. $\left(^{\star \star}\right) P$-value $<0.01$. (B) T47D-MTVL cells were transfected with either control, SRA-specific, HOTAIR-specific, or GAS5-specific siRNAs and lysed; total RNA was prepared; and cDNA was generated and used as template for real-time PCR with specific primers for luciferase, STAT5A, BCL-X, and EGFR genes. The values were normalized with GAPDH and represent the mean and standard deviation from three experiments performed in duplicate. $\left(^{\star}\right) P$-value $<0.05$. $(C)$ T47D-MTVL cells were transfected with control or SRA-specific siRNAs; after $48 \mathrm{~h}$, cells were transfected with wild-type or a SRA mutant version resistant to the siRNA-mediated knockdown. After $24 \mathrm{~h}$, RNA was prepared, and SRA, BIRC3, and STAT5A gene activity was measured as shown before. The values were normalized with GAPDH and represent the mean and standard deviation from two experiments performed in duplicate. $\left(^{\star}\right) P$-value $<0.05$. 
Vicent et al.

A

RNA immunoprecipitation

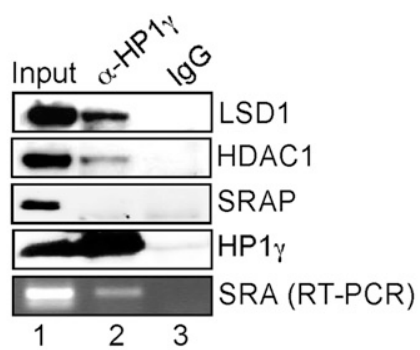

C

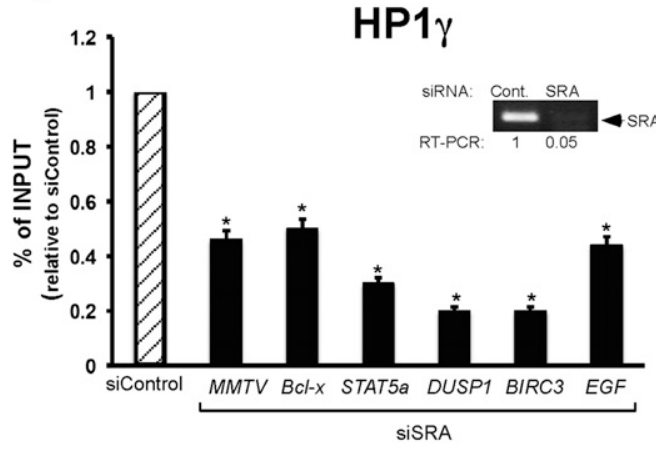

B

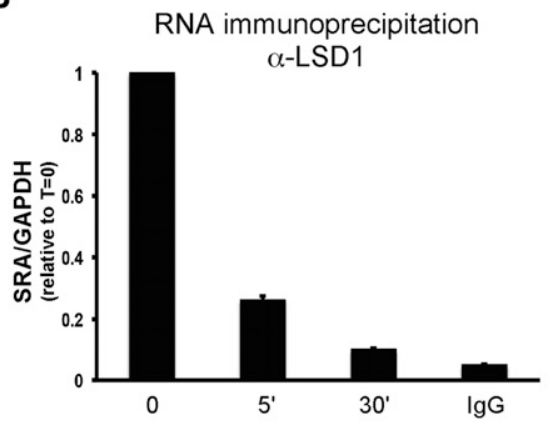

D
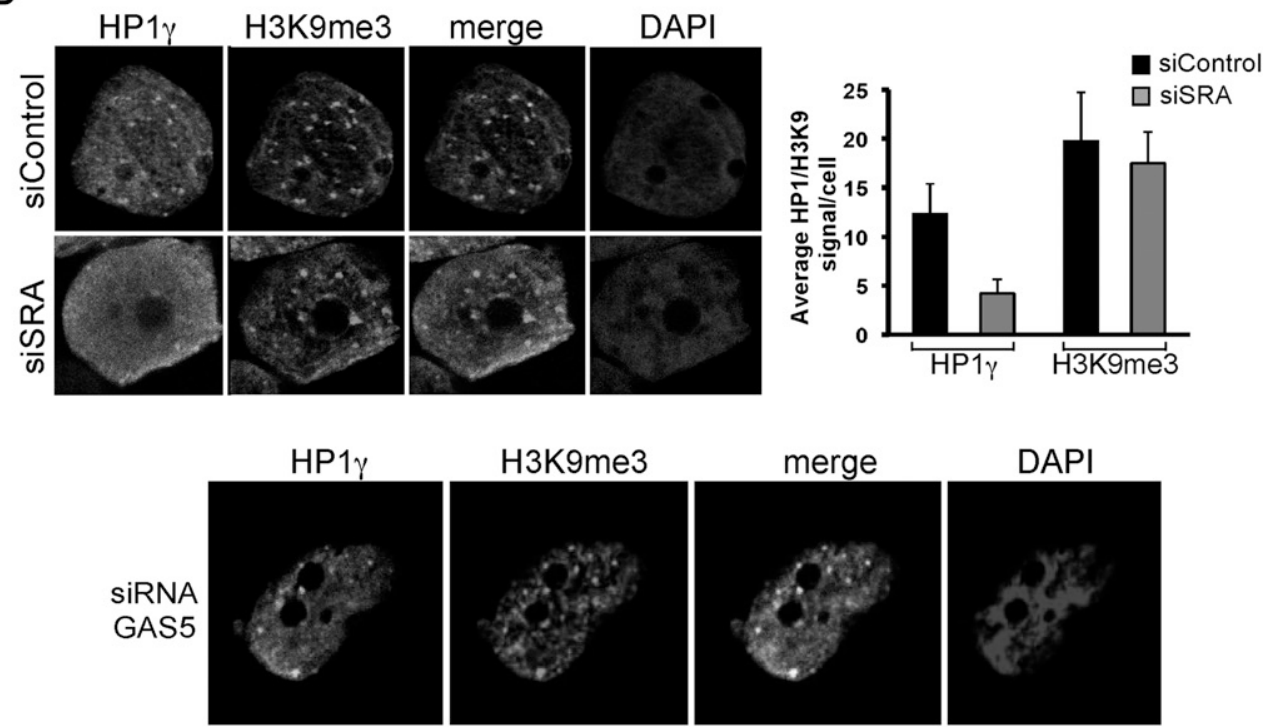

Figure 5. The SRA RNA is involved in repressive complex anchoring to chromatin. (A) T47D-MTVL cells were lysed and immunoprecipitated with either $\alpha-\mathrm{HP} 1 \gamma$-specific antibody or mouse IgG and separated into two fractions for RNA and Western blot analysis. (Bottom panel) Either the immunoprecipitates were analyzed by immunoblotting with LSD1-, HDAC1-, SRAP-, and HP1 $\gamma$ specific antibodies or total RNA was extracted and subjected to RT-PCR with the primers specific to SRA. $(B)$ Cells were treated with hormone for the indicated times and immunoprecipitated with either $\alpha$-LSD1-specific antibody or rabbit IgG, and total RNA was extracted and subjected to RT-PCR with the primers specific to SRA and GAPDH. The values represent the mean and standard deviation from three experiments performed in duplicate. $(C)$ Cells were transfected with either control or SRA-specific siRNAs and subjected to ChIP assays using HP1 $\gamma$ and PR antibodies. DNA was analyzed for the presence of MMTV nucleosome $\mathrm{B}, B C L-X, D U S P 1$, $S T A T 5 A, B I R C 3$, and EGF PRbs. The values represent the mean and standard deviation from three experiments performed in duplicate. $\left.{ }^{\star}{ }^{\star}\right) P$-value $<0.05$. The degree of depletion of SRA RNA is depicted. $(D)$ Cells were transfected with either control, SRA-specific (top panels) or GAS5-specific (bottom panel) siRNAs; fixed; and immunostained with HP1 $\gamma$ and H3K9me3-specific antibodies or DAPI. (Right panel) T47D-MTVL cells were transfected with the indicated siRNA, and the number of HP1 or H3K9me3 dots per cell was counted using the ImageJ software for three different images per condition. 
data not shown). However, under conditions of SRA depletion, we found an increase of PR binding to target genes (Fig. 5C, right panel). Thus, SRA interacts with and stabilizes the repressive complex, and its absence increased the basal transcriptional activity of PR target genes by displacing HP1 $\gamma$-LSD1. In addition, immunofluorescence studies using confocal microscopy in control and SRAdepleted cells showed a loss of HP1 $\gamma$ signal after specific SRA knockdown, indicating that the role of SRA could be more general than originally expected (Fig. 5D). As control, interference of GAS5 failed to change HP1 $\gamma$ distribution (Fig. 5D, bottom panel).

In order to confirm that SRA associates with the genomic sites bound by the HP1 $\gamma$-LSD1 complex, we performed ChIP assays using antisense oligos (Mariner et al. 2008). SRA preferentially associated with the PR target sites of the MMTV and STAT5A genes, which we showed to be dependent on the HP1 $\gamma$-LSD1-repressive complex (Supplemental Fig. S8). Upon hormone treatment, we detected $40 \%-50 \%$ displacement of SRA in these genomic sites (Supplemental Fig. S8). No enrichment was observed with a control antisense oligo (Mariner et al. 2008) or in a control region that does not present uPRbs (Supplemental Fig. S8). Thus, SRA is part of the HP1 $\gamma$ LSD1.com-repressive complex, which is anchored by uPR to its genomic target regions and is displaced after hormone.

Genomic binding regions of the HP1 $\gamma$-LSD 1 complex colocalize with uPRbs and are associated with hormone-regulated genes

To explore whether the role of the HP1 $\gamma$-LSD1 complex described is observed genome-wide, we performed ChIPseq in T47D-MTVL cells with specific antibodies to HP1 $\gamma$, LSD1, and $\mathrm{H} 3 \mathrm{~K} 9 \mathrm{me} 3$. After aligning the sequence reads to the human genome (see the Materials and Methods), we identified 6059 and 12,962 sites for LSD1 and HP1 $\gamma$, respectively $(P$-value $<0.001$, fold enrichment $\geq 6)$. HP1 $\gamma$ and LSD1 peaks were located mainly in intergenic regions $(56.1 \%$ and $53.1 \%$, respectively) and introns $(36.8 \%$ and $41.1 \%$, respectively), and only a small fraction were located in promoter regions $(2.8 \%$ and $1.6 \%)$. Analysis of the average LSD1 read intensity profiles showed a distribution that peaks at the center of HPl $\gamma$-binding regions, indicating a preferential location of HP1 $\gamma$ overlapping with LSD1 sites (Fig. 6A, left panel). In fact, 1766 sites ( $7 \%$ of the total LSD1 regions) colocalized with HP1 $\gamma$ ( $0.9 \%$ expected by random distribution). The same profile was observed when the reciprocal data were plotted (Supplemental Fig. S9A). No enrichment in the profiles was detected when random sequences instead of LSD1or HP1 $\gamma$-binding sites were used (Fig. 6, bottom panel; Supplemental Fig. S9A, bottom panel). The average read profile of $\mathrm{H} 3 \mathrm{~K} 9 \mathrm{me} 3$ peaks at the center of HP1 $\gamma$ and LSD1 sites (Fig. 6A, right).

Next, we tested whether LSD1 and HP1 $\gamma$ colocalize over the genomic uPRbs in the absence of hormone (uPRbs). In a previous study, we identified 25,000 genomic PRbs after progestin treatment but $<1000$ binding sites for the UPR prior to hormone treatment (Ballare et al. 2013). However, the recent progress in DNA sequencing technology allowed us to increase the coverage 10-fold and identify $6876 \mathrm{uPRbs}\left(P\right.$-value $\left.<10^{-14}\right)$. Some of these sites were validated by ChIP and showed an average increase of 6.7-fold versus control IgG (Fig. 3A; Supplemental Fig. S9B). Among others, binding of uPR was found in MMTV, STAT5A, EGFR, and BCL-X genes, known to be dependent on the HP1 1 -LSD1-repressive complex (Supplemental Fig. S10). On the other hand, no binding of uPR was detected in the Jun gene, shown to be independent on HP1 $\gamma$-LSD1 (Fig. 1F; Supplemental Fig. S10).

Analysis of the read intensity profiles of HPl $\gamma$ and LSD1 in the absence of hormone showed a distribution that peaks at the center of uPR-binding regions (Fig. 6B), confirming previous results obtained in individual genes (Fig. 3A). A partial reduction in the profile of HPl $\gamma$ and LSD1 was observed $30 \mathrm{~min}$ after hormone addition (Fig. 6C; Supplemental Fig. S9C). Interestingly, in 4773 sites $(67 \%)$ of the uPRbs, HP1 $\gamma$ changed after hormone. Therefore, the HP1 $\gamma$-LSD1-repressive complex colocalizes with the PRbs, and its global distribution is influenced by the presence of the hormone.

To find out whether the change in the distribution of HP1 $\gamma$ and LSD1 after hormone is due to displacement of these proteins from certain PRbs, we classified HPly sites at time 0 according to the overlapping with PRbs (Fig. 6D). Interestingly, we found that in $60 \%$ of these sites, HP1 $\gamma$ is displaced after hormone; in $30 \%$, it is recruited (Fig. 6D, top and bottom panels, respectively); and in $10 \%$, it remained unchanged upon hormone addition (Fig. 6D, middle panel). Quantification of the read intensity profiles from the top $20 \%$ of these three types of sites are shown in Figure 6D (right panels). Thus, hormone induction changed HP1 $\gamma$ distribution, and the repressive complex could be either evicted or recruited to hormoneresponsive regions. One interesting feature is that sites in which HP1 $\gamma$ is displaced upon hormone treatment were 2.3 -fold enriched in promoter regions $\mid<1000 \mathrm{bp}$ from the TSS).

We then investigated whether the HP1 $\gamma$ sites both recruited and displaced after hormone are preferentially associated with hormone-regulated genes. In order to address this question, we performed RNA sequencing (RNA-seq) experiments using RNA obtained from T47DMTVL cells untreated or treated for $6 \mathrm{~h}$ with hormone. After hormone treatment, 2201 genes (11.3\%) were downregulated, and 2065 genes (10.6\%) were up-regulated (Supplemental Fig. S11A). We found that uPRbs are enriched in hormone-activated genes compared with down-regulated or nonregulated genes $(44 \%$ vs. $30 \%$ and $25.9 \%$, respectively, window: $-20 \mathrm{~kb}$ per gene bodyl (Supplemental Fig. S11B). Combining the results of the ChIP-seq of HP1 $\gamma$ and PR (Ballare et al. 2013) with the RNA-seq, we found that changes in HP1 $\gamma$ binding to PRbs are significantly enriched in and around genes regulated by hormone $30.8 \%$ for hormone-regulated genes vs. $5.3 \%$ for nonregulated genes; $P<2.2 \times 10^{-16}$ ) (Supplemental Fig. S9D). The fact that the repressive complex is recruited to certain hormone-regulated genes 
A
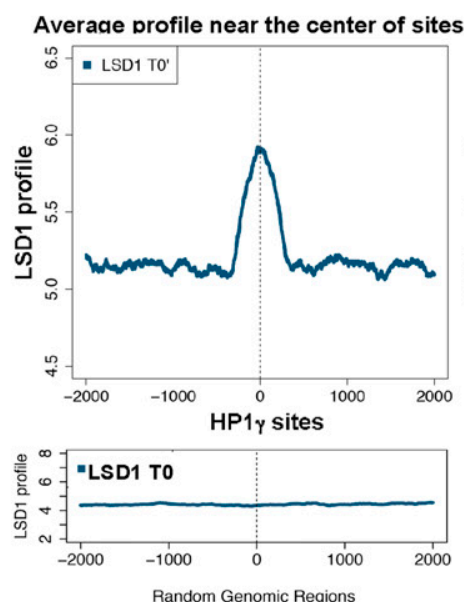

C

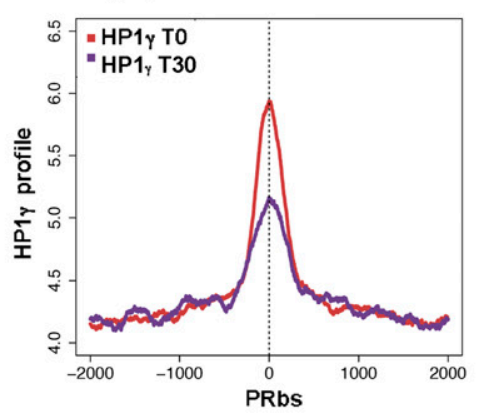

$\mathbf{E}$

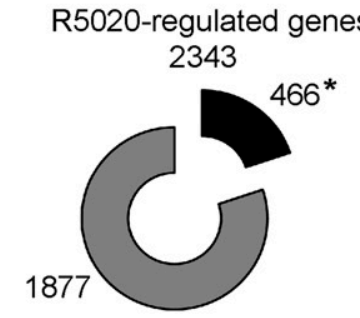

* Genes affected by SRA depletion

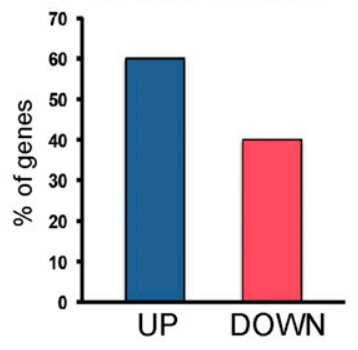

B

D

F

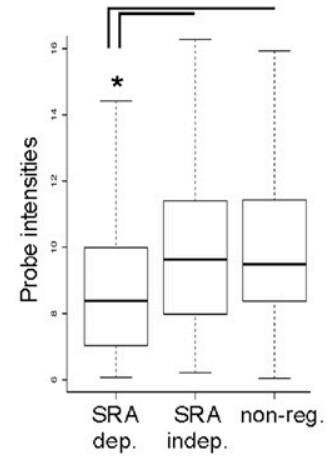

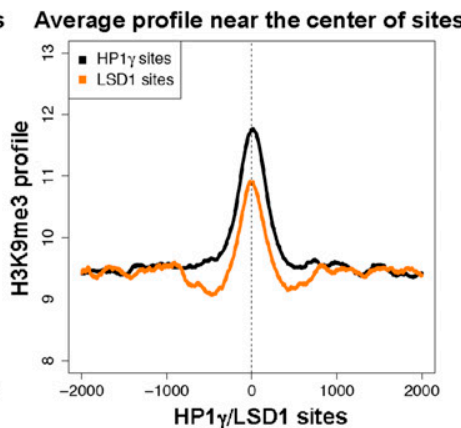

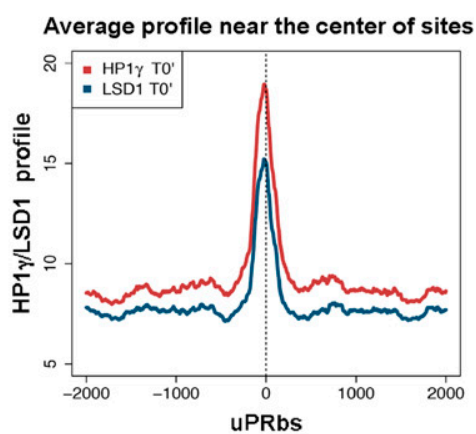

ormone-dependent displacement of HP1 $\gamma$

DP1 $\gamma$

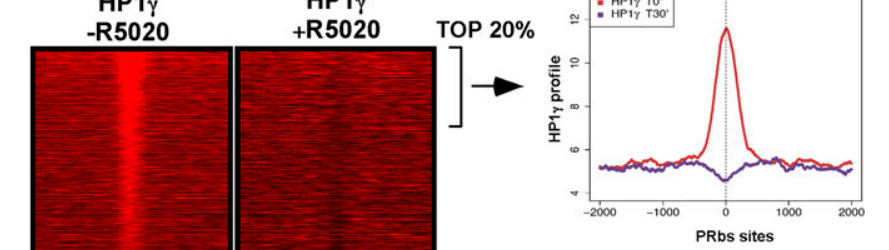

Hormone-independent

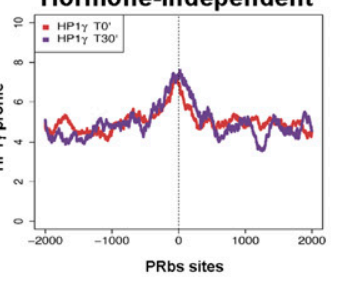

Hormone-dependent recruitment of HP1 $\gamma$

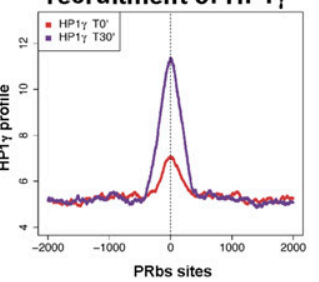

G

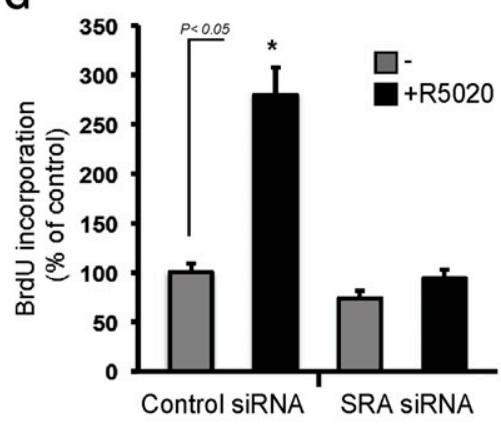

Figure 6. HP1 $\gamma$-LSD1.com genomic binding regions colocalize with PRbs and are associated with hormone-regulated genes. $(A)$ Genomic distribution of LSD1 and HP1 $\gamma$. Based on the analysis of ChIP-seq experiments performed for LSD1, HP1 $\gamma$, and H3K9me3, we generated a graphic of the distribution of the reads centered all over the indicated regions associated with each of these proteins. The number of HP1 $\gamma$ - and LSD1-binding regions used in this analysis was 12,962 and 6059 , respectively $\left(P\right.$-value, $10^{-3}$; fold enrichment $\left.\geq 6\right)$. (Bottom panel) The enrichment of LSD1 and HP1 $\gamma$ is not observed when random sequences located $50 \mathrm{~kb}$ away from the regions of interest were used for the alignment (data not shown). (B) Genome-wide distribution of HPly and LSD1 binding around uPRbs. $(C)$ Prior to hormone administration (red curve), a preference of HP1 for PR-binding sequences is observed. After 30 min of hormone treatment (blue curve), a partial depletion of HP1 binding around the PR sites is observed. $(D, L e f t)$ Heat maps of HPl $\gamma$ before and after hormone treatment around all of the PRbs $( \pm 2 \mathrm{~kb})$. (Right) The three figures represent the average profiles of the top $20 \%$ subsets of PRbs $( \pm 2 \mathrm{~kb})$. (E) T47D-MTVL cells transfected with control siRNA or siRNA against SRA were induced or not with hormone, and the extracted RNA was hybridized to a gene expression array. (Top panel) Analysis of microarray data found 466 genes regulated by hormone affected by the SRA knockdown. (Bottom panel) Sixty percent and $40 \%$ of them fall into the groups of up-regulated and down-regulated genes, respectively. $(F)$ Up-regulated genes affected by SRA presented lower basal activity compared with SRA-independent or nonregulated genes. $\left({ }^{\star}\right) P$-value $<0.013$. $(G)$ SRA knockdown reduces R5020-induced cell proliferation of T47D-MTVL cells. Bars represent mean $\pm \operatorname{SD}(n=5)$. $\left({ }^{\star}\right) P$-value $<0.05$. 
suggests that the complex may also be involved in hormone-mediated gene repression. We classified PRbs from which HP1 $\gamma$ is displaced according to their proximity to up-regulated and down-regulated genes obtained by RNA-seq. We found that HPl $\gamma$ displacement was observed preferentially in the PRbs of up-regulated genes $\left(22 \%\right.$ vs. $9.7 \%$ of the down-regulated genes; $P<1.7 \times 10^{-7}$ ) (Supplemental Fig. S9E). STAT5A and BCL-X genes previously shown to be dependent on the repressive complex (Fig. 1 F) are included in the top $20 \%$ of the group that lose HP1 $\gamma$ upon hormone induction.

Next, we asked whether these up-regulated genes, which have uPRbs, are functionally linked. Gene ontology (GO) analysis showed that among the top 10 more enriched terms, the functional term negative regulation of apoptosis is significantly overrepresented $(P<0.05$ and FD5 $<5 \%$ ) (Supplemental Fig. S12). In conclusion, the HP1 $\gamma$-LSD1-repressive complex is a key element involved in hormone-dependent regulation of a subset of inducible genes involved in relevant cellular functions as regulation of apoptosis.

The SRA RNA controls hormone-regulated genes and cell proliferation

In order to explore the global function of SRA, T47DMTVL cells were transfected with control siRNA or siRNA against SRA and induced with hormone for $6 \mathrm{~h}$. The extracted RNA was analyzed using a SurePrint G3 human gene expression $8 \times 60 \mathrm{~K}$ array (Agilent). SRA had a general effect in transcription in T47D cells, as 502 genes were up-regulated by SRA knockdown in the absence of hormone. Thus, although first reported as a hormonal coactivator, SRA could be more generally involved in either activation or repression of genes. We found that, of the 2343 genes regulated by hormone, $466(20 \%)$ were affected by SRA knockdown (Fig. 6E, top panel). Of these, $60 \%$ were up-regulated, and $40 \%$ were down-regulated by hormone (Fig. $6 \mathrm{E}$, bottom panel). From the 466 SRAdependent genes, $57.8 \%$ and $44 \%$ contained PR- or HPl $\gamma$ binding sites within $5 \mathrm{~kb}$ upstream of the transcription start site (TSS) and transcription termination site (TTS). Interestingly, we found that hormone-induced genes regulated by SRA presented very low basal activity compared with SRA-independent or nonregulated genes (Fig. 6F). This suggests that the subset of genes for which regulation by hormone is SRA-dependent consists of those that need to be tightly silenced prior to hormone treatment.

Further analysis of the SRA-affected genes showed that $10 \%$ of the up-regulated genes were significantly better induced, while $6.8 \%$ were less induced in the absence of SRA. GO analysis showed that SRA-affected genes are associated with regulation of transcription and phosphorylation, cell proliferation, apoptosis, DNA binding, intracellular signaling cascade, and signal transduction (Supplemental Fig. S13A).

To examine whether SRA regulates proliferation of tumor cells, we monitored progestin-dependent cell growth by quantifying proliferation of cells transfected with SRA siRNA. Compared with cells transfected with an unrelated control siRNA, progestin-induced proliferation is reduced by SRA knockdown (Fig. 6G; Supplemental Fig. S5C), while serum-induced cell proliferation was not affected (fold change: $1.9 \pm 0.2$ vs. $2.2 \pm 0.15$ for control and SRA-depleted cells, respectively), thus underlining the importance of the SRA in the control of PRdependent growth of tumor cells.

Analysis of the GO terms of the genes affected by the SRA knockdown and with uPRBs revealed that these genes are associated with negative regulation of apoptosis (Supplemental Figs. S12, S13A). To test whether the repressive complex is involved in apoptosis, we analyzed the effect of depleting SRA in staurosporine-induced apoptosis in T47D cells. Incubation of control cells with staurosporine for $48 \mathrm{~h}$ increased PARP cleavage, an indicator of apoptosis (Supplemental Fig. S13B, lanes 1,2). In cells depleted of SRA, this effect of staurosporine was diminished, in agreement with the suggested role of SRAregulated genes (Supplemental Fig. S13B, lanes 3,4).

\section{Discussion}

Steroid hormones modulate the activity of many genes in their target cells via their intracellular receptors, which can mediate up-regulation or down-regulation of gene expression. In general, this is achieved by either increasing or decreasing the percentage of transcriptionally active genes in the cell population (Ko et al. 1990). Activating a gene may first require counteracting the repressive machinery that keeps the gene silent, a process known as derepression, eventually followed by the recruitment of transcriptional activators. In this study, we identify the HP1 $\gamma$-LSD1-repressive complex as a pivotal factor involved in silencing of a subset of hormoneinducible genes. We found that the uPR, RNA SRA, and HP1 $\gamma$ protein participate in the proper anchoring of the repressive complex to chromatin. Upon hormone addition, cross-talk with kinase signaling leads to phosphorylation of histone $\mathrm{H} 3$ at $\mathrm{S} 10$, which facilitates displacement of the repressive complex.

\section{Genomic targeting of the HP1 $\gamma-L S D 1$-repressive complex needs $u P R$}

HP1 proteins are preferentially found in heterochromatin that is enriched in histone $\mathrm{H} 3$ tails methylated on K9. However, H3K9me3 histones are found throughout the nuclear genome (Peters et al. 2001; Maison et al. 2002), but in T47D breast cancer cells, HP1 $\gamma$ is enriched in the vicinity of PRbs, suggesting that the methyl-binding activity of HP1 proteins is not sufficient for their targeting to specific sites in inactive chromatin. We found that levels of H3K9me3 were not particularly enriched in sites bound by the HP1 $\gamma$-LSD1 complex compared with adjacent sequences (Fig. 3A). We hypothesize that uPR could target the repressive complex to the PRbs, as shown previously with different nuclear receptors and corepressors (Sachs et al. 2002; Weston et al. 2003). In support of this hypothesis, we found interaction of uPR with the HPl $\gamma-$ LSD1 complex as well as colocalization of uPR and HP1 $\gamma$ 
or LSD1 genome-wide. Moreover, recombinant PR binds directly to HP1 $\gamma$ in vitro, and in untreated cells lacking $\mathrm{PR}$, the repressor complex is not loaded on inducible promoters, which show the same enhanced transcriptional activity as cells lacking LSD1 or HP1 $\gamma$. Thus, although H3K9me3 is involved in HP1 $\gamma$-LSD1 anchoring, $\mathrm{uPR}$ is important for targeting the complex to PRbs.

We found 371 uPRbs $(5.2 \%$ of the total) associated with HP1 $\gamma$, and these sites were higher (more reads per peak) compared with uPRbs that do not overlap with HP1 $\gamma$. Searching for other sequence motifs in this set of overlapping uPRbs revealed a 2.3-fold enrichment (3.4 Z-score) on the binding sequence for CDF-1, a protein involved in repression of cell cycle target genes (Zwicker et al. 1998). Whether CDF-1 really binds to these sites and has a function in regulation of the cell cycle remains to be investigated.

Interestingly, a recent study suggested that the ancestral steroid receptor functioned in a ligand-independent manner (Thornton et al. 2003). In fact, unliganded receptors can execute their own gene expression program, as reported for the $\mathrm{AR}$, resulting in androgen-independent growth (Wang et al. 2009). Expression of PR in MCF-7 cells in the absence of ligand markedly disrupts the effects of estrogen on cell growth and gene expression (Zheng et al. 2008). Thus, the unliganded receptor has an important role and, according to our model, could be linked to the repression of genes associated with cell proliferation and inhibition of apoptosis. In addition, GO analysis of the up-regulated genes that have uPRbs showed a significant enrichment in the functional term inhibition of apoptosis $(P<0.05$, false discovery rate $[\mathrm{FDR}]<5 \%$, gene window: $-20 \mathrm{~kb}$ per gene body). In fact, after SRA knockdown, genes associated with these processes were preferentially affected (Supplemental Fig. S13). In fact, staurosporine-induced apoptosis of T47D cells was reduced after SRA knockdown (Supplemental Fig. S13B).

\section{The PR-associated RNA SRA is required for proper repressive complex loading}

Given the function of ncRNA in chromatin repression (Kurokawa 2011) we explored a possible participation of ncRNAs in recruitment of the HP1 $\gamma$-LSD1-repressive complex. The nuclear receptor coactivator SRA, which encodes a protein (SRAP) that antagonizes the effect mediated by SRA (Hube et al. 2011), plays an important role in mediating estradiol action by interacting with the coactivator SRC1 (Lanz et al. 1999). Another protein that interacts with SRA is SLIRP, which is located mainly in the mitochondria but is actively recruited to promoters of nuclear receptors. Depletion of SLIRP increased the binding of ER to the TFF1 promoter in the absence of hormone, and this may explain the change in promoter state upon SRA depletion (Hatchell et al. 2006). We did not observe interaction of SLIRP with the HP1 $\gamma-$ LSD1.com complex (Supplemental Fig. S1A), and depletion of SLIRP or SHARP affected a subset of genes different from that affected by SRA knockdown (data not shown). Moreover, interaction of PR with SRA was only partially competed with STR7, the structure required for SRASLIRP/SHARP interaction (Supplemental Fig. S7B). Thus, our results suggest that in T47D cells, HP1 $\gamma$-LSD1.com and SRA-SLIRP/SHARP are different complexes. Most of the experiments demonstrating the coactivator function of SRA were performed with transiently transfected reporter genes that lack a proper chromatin organization (Archer et al. 1992). Recently, a set of microarrays studies depleting SRA in MCF7 cells and testing the response to estrogen of endogenous genes showed that SRA levels affect only mildly the activity of genes that require direct binding of the ER to DNA (Foulds et al. 2010). In fact, some genes, such as TFF1 and ACOX2, showed a twofold increase in their basal activity, indicating that SRA may also have a repressive role.

In T47D cells not treated with hormone, SRA stabilized the binding of the HP1 $\gamma$-LSD1 complex to uPRbs. We found that $\sim 470$ hormone-regulated genes depend on SRA, and $60 \%$ of them exhibited very low basal activity and were up-regulated by SRA knockdown. This indicates that SRA contributes to repression of key genes that must be silent in the absence of hormone. SRA can act as a corepressor of these genes by contributing to anchoring the repressive complex. SRA interacts with PR, LSD1, and HP1 proteins (Fig. 5), and its depletion leads to destabilization of the complex and therefore displacement of HP1 $\gamma$ and LSD1 from target genes (Fig. 5C; Supplemental Fig. S4C). Moreover, SRA seems to have a more general effect than originally suspected, as SRA depletion changed cellular HP1 $\gamma$ localization in immunofluorescence experiments (Fig. 5D). For this function, SRA would have to act in trans in different genomic loci, reminiscent of what has been previously shown for HOTAIR ncRNA (Gupta et al. 2010).

Although we cannot rule out the possibility that the general effect of SRA depletion could be due to the absence of the protein SRAP, we have evidence supporting a role for the RNA itself. First, we found a delocalization of HP1 $\gamma$ and LSD1 shortly after RNase treatment (Fig. 4A). Second, transfection with a SRA version that cannot be translated into protein decreased the basal activity of target genes (Supplemental Fig. S6A), and a mutant SRA without coding potential rescued the depletion of endogenous SRA (Fig. 4C). Third, the repressive complex interacted with RNA of SRA, while no interaction with SRAP was detected (Fig. 5A). Fourth, direct interaction of PR with SRA was detected in in vitro binding assays (Supplemental Fig. S7). Therefore, genomic anchoring and targeting of the HP1 $\gamma$-LSD1repressive complex required the $\mathrm{UPR}$ as well as its associated RNA SRA, which could act as a scaffold for binding of the HP1 $\gamma$-LSD1 complex to chromatin, as previously shown for HOTAIR and LSD1 (Tsai et al. 2010).

A question that arises is whether SRA acts in cis or in trans. We checked the effect of SRA knockdown on the activity of genes located in its proximity. In a window of $100 \mathrm{~kb}$ around $S R A$, we found 10 genes, and none of them changed their activity after SRA depletion. The increase in the window size to $2 \mathrm{Mb}$ included 75 genes around SRA and showed similar results. Moreover, the 
SRA gene is located in chromosome 5 , and its depletion affected the activity of $B C L-X, B I R C 3, S T A T 5 A$, and KRT23, genes placed in chromosomes 20,11, and 17, respectively. Thus, these results indicate that the SRA RNA acts in trans and would follow the same trend as other long ncRNAs (Guttman et al. 2011).

How do our findings fit with the original discovery of SRA? The SRA-HP1 $\gamma$-PR-LSD1.com complex described here presents features different from those previously reported for SRA-containing complexes (Lanz et al. 1999; Hatchell et al. 2006). The complex is already formed in the absence of hormone, is involved in basal repression, exhibits no interaction with SRC1 or SLIRP (Fig. 3C; Supplemental Fig. S1A), and is required for repression in the presence of hormone (data not shown). Therefore, we conclude that SRA-HP1 $\gamma$-PR-LSD1.com is a novel complex. Of course, we cannot exclude that SRA could be involved in hormone-dependent gene activation as part of a different complex.

\section{Hormone treatment activates different signaling pathways required for repressive complex eviction}

In cells with the $M M T V$ gene promoter integrated in chromatin, the promoter is silenced by a complex containing HP1 $\gamma$ that is displaced upon recruitment of the ligand-activated PR complex with the Msk1 kinase, which phosphorylates histone H3 on Ser 10 (Vicent et al. 2006). Thus, a "phospho/methyl switch" controls the dynamic association of HP1 $\gamma$ with the MMTV target (Fischle et al. 2005; Vicent et al. 2006). In the present study, we found that HP1 $\gamma$ is part of a repressive complex including LSD1, HDAC1/2, COREST, and BRAF35. In fact, we found that a direct interaction between HP1 $\gamma$ and LSD1 and depletion of either HDAC1 or LSD1 increased the basal activity of a subset of progesterone target genes as well as the corresponding post-translational modificationsH3K14ac and H3K4me3, respectively. The relevance of the "phosphor/methyl switch" for anchoring/displacement of the repressive complex is confirmed by the effect of the H3 mutant with S10 substituted by alanine (H3S10A), which precludes displacement of the HP1 $\gamma$-LSD1 complex from target regions upon hormone addition. However, we cannot rule out that post-translational modifications of HP1 $\gamma$ itself influences the interactions with partner proteins, as phosphorylation of HP1 $\gamma$ on S 83 impairs its silencing activity and serves as a marker for transcriptional elongation (Lomberk et al. 2006). In addition, phosphorylation of HP1 $\alpha$ (S11-S14) and HP1 $\beta$ (S51) plays a critical role in modulating efficient binding to the methylated histone $\mathrm{H} 3$ tail and regulates mobilization during the initiation of the DNA damage response (Ayoub et al. 2008; Hiragami-Hamada et al. 2011). Nevertheless, the biological functions of HP1 phosphorylation in mammals remain largely unclear.

Finally, other histone modifications could contribute to displacement of the repressive complex and proper gene activation. It has been reported that PARP1 can parylate the demethylase KDM5B and regulate its recruitment to target sites (Krishnakumar and Kraus 2010). Since
PARP1 is involved in hormone action (Wright et al. 2012) and KDM5B is part of the repressive complex, it is conceivable that both events are linked.

Recently, we uncovered the fact that during the first minute of hormone-dependent gene activation, five different remodeling machineries (NURF, CDK2, PARP1, ASCOM, and KDM5B) cooperate in a coordinate manner to displace the linker histone H1 (Vicent et al. 2011; Wright et al. 2012). It is not clear whether $\mathrm{H} 1$ is evicted in association with other components of the repressive complex, such as HPl $\gamma$, although both proteins are displaced very rapidly from the MMTV promoter. Moreover, the linker histone H1.4 can interact with HP1, and their association is mediated by the methylation of H1.4 at K26 (Daujat et al. 2005). The chromodomain of HP1 mediates binding to methylated $\mathrm{K} 26$ of $\mathrm{H} 1$, which is prevented by CDK2-dependent phosphorylation of H1.4 (Daujat et al. 2005). We showed that progestins induce rapid activation of CDK2 that is required for $\mathrm{H} 1$ displacement and PARP1 activation (Wright et al. 2012). Thus, H1 phosphorylation mediates its eviction from target chromatin and could participate in HP1 $\gamma$ displacement. On the other hand, H3S10 phosphorylation mediates the displacement of HPl $\gamma$ from target chromatin by inhibiting its interaction with $\mathrm{H} 3 \mathrm{~K} 9 \mathrm{me}$. Thus, in order to respond to external stimuli, eukaryotic cells dispose of very rapid phosphorylation-mediated mechanisms to ensure displacement of repressive components from genes that must be activated. How all of these different kinase pathways activated by hormones are interconnected is still unclear.

\section{Model}

We propose that hormone-dependent gene regulation in the breast cancer cell line T47D requires the HP1 $\gamma$-LSD1repressive complex for silencing a subset of genes that are activated by hormone. This complex is anchored to genomic target sites by the unliganded receptor, its associated RNA SRA, and H3K9me3 (Supplemental Fig. S14). In the presence of hormone, several signaling pathways are activated, among them ERK1/2 and the downstream kinase MSK1 (Vicent et al. 2006). Activated MSK1 phosphorylated $\mathrm{H} 3$ at $\mathrm{S} 10$ and promoted HP1 $\gamma$-LSD1 eviction from target regions (Supplemental Fig. S14). Displacement of the repressor complex allows $\mathrm{H} 3$ to be trimethylated at K4 and acetylated at K14, both marks required for NURF and BAF loading and chromatin remodeling necessary to allow binding of PR complexes containing coactivators that will promote gene transcription (Vicent et al. 2009, 2011).

\section{Materials and methods}

\section{Cell culture and hormone treatments}

T47D-MTVL breast cancer cells carrying one stably integrated copy of the luciferase reporter gene driven by the MMTV promoter (Truss et al. 1995) were routinely grown in RPMI 1640 medium supplemented with $10 \%$ FBS, 2 mM L-glutamine, $100 \mathrm{U} / \mathrm{mL}$ penicillin, and $100 \mu \mathrm{g} / \mathrm{mL}$ streptomycin. For the 
experiments, cells were plated in RPMI medium without phenol red supplemented with $10 \%$ dextran-coated charcoal-treated FBS (DCC/FBS) and, 48-h later, medium was replaced by fresh medium without serum. After $24 \mathrm{~h}$ in serum-free conditions, cells were incubated with R5020 (10 nM) for different times at $37^{\circ} \mathrm{C}$.

Stable expression of Flag-tagged histone $\mathrm{H} 3$ wild type and S10A mutant in T47D-MTVL cells

The pCMV-Tag2A construct containing the full-length human Histone H3.1 was used as a template for the generation of the Histone H3 S10A point mutation construct by site-directed mutagenesis with QuickChange II mutagenesis kit (Agilent Technologies). The DNA encoding for both human wild-type histone H3.1 and the S10A mutant were cloned into the pLPCX retroviral expression vector. These vectors were used to infect T47D-MTVL cells. Infected cells were cultured in medium containing $2 \mathrm{mg} / \mathrm{mL}$ puromycin starting from the day after the infection.

\section{ChIP in cultured cells}

ChIP assays were performed as described (Strutt and Paro 1999) using anti-PR (Santa Cruz Biotechnology, H190); anti-HP1 $\gamma$ (Mab 3450), anti-COREST (07-455), anti-H3S10phos (17-685, Ab+), and anti-H3K14ac from Millipore; anti-LSD1, H3K9me3, H3K4me3, and HDAC1 from Abcam; anti KDM5B from Cell Signaling; anti MSK1 (Santa Cruz Biotechnology, H65); and anti-Flag (Sigma).

Quantification of ChIP was performed by real-time PCR using LightCycler (Roche). The fold enrichment of the target sequence in the immunoprecipitated compared with the input (Ref) fractions was calculated using the comparative Ct (the number of cycles required to reach a threshold concentration) method with the equation $2^{\mathrm{Ct}(\mathrm{IP})}-\mathrm{Ct}(\mathrm{Ref})$. Each of these values was corrected by the human $\beta$-globin gene and referred to as relative abundance over time 0 . Primer sequences are available on request.

For RNase treatment on digitonin-permeabilized T47DMTVL cells (Liu et al. 1999), titration experiments (RNase concentration, time, and temperature) allowed us to determine optimal conditions with incubation for $5 \mathrm{~min}$ at $23^{\circ} \mathrm{C}$ in $1 \mathrm{mg} / \mathrm{mL}$ RNase A (Fermentas) in PBS. We then rinsed cells twice in PBS before cross-linking for ChIP experiments.

\section{RNAi experiments}

All siRNAs were transfected into the T47D-MTVL cells using Lipofectamine 2000 (Invitrogen). After 48 h, the medium was replaced by fresh medium without serum. After $1 \mathrm{~d}$ in serum-free conditions, cells were incubated with R5020 (10 nM) or vehicle (ethanol) for different times at $37^{\circ} \mathrm{C}$. The down-regulation of LSD1, HDAC1, and HP1 $\gamma$ expression was determined by Western blotting. The down-regulation of SRA1, HOTAIR, and GAS5 was determined by measuring the RNA levels using real-time PCR. Primer sequences are available on request. Stable LSD1depleted T47D-MTVL cells were generated by using lentiviral shRNAs obtained from Sigma (MISSION shRNA lentiviral transduction particles). SRA siRNAs were purchased from Dharmacon (Thermo Scientific); HOTAIR, HP1 $\gamma$, GAS5, HDAC1 siRNAs were purchased from Santa Cruz Biotechnology.

For rescue experiments, T47D-MTVL cells were transfected with control or SRA-specific siRNAs; after $48 \mathrm{~h}$, cells were transfected using Lipofectamine 2000 with either the SRAcontaining pSCT1 plasmid (Lanz et al. 1999) or a mutant version of SRA resistant to the siRNA-mediated knockdown. After $24 \mathrm{~h}$,
RNA was prepared, and $S R A, B I R C 3$, and $S T A T 5 A$ gene activity was measured (see below). The mutant version of SRA was constructed by using the QuickChange II XL site-directed mutagenesis kit (Agilent).

\section{RNA extraction and RT-PCR}

Total RNA was prepared, and cDNA was generated as previously described (Vicent et al. 2006). Quantification of LUC and GAPDH gene products was performed by real-time PCR. Each value calculated using the standard curve method was corrected by the human GAPDH and expressed as relative RNA abundance over time 0. Primer sequences for SRA, BCL-X, STAT5A, EGF, JUN, BIRC3, DUSP1, and CCND1 are available on request.

\section{Co-IP assay}

Cells were lysed, and cell extracts (1 $\mathrm{mg}$ of protein) were incubated with protein G/A agarose beads previously coupled with $6 \mu \mathrm{g}$ of the corresponding antibodies or a nonspecific control antibody. The immunoprecipitated proteins were eluted by boiling in SDS sample buffer. Inputs and immunoprecipitations were analyzed by Western blot using KDM5B, LSD1, HDAC1, HDAC2, COREST, G9a (Cell Signaling), HP1 $\gamma$, SRC1 (Abcam), SRAP (Bethyl Laboratories), SLIRP (Santa Cruz Biotechnology, F12), and PR-specific antibodies.

\section{RIP}

The RIP protocol was performed as described previously with the following modifications (Niranjanakumari et al. 2002; Tsai et al. 2010): Six million cells per condition were treated with $0.3 \%$ formaldehyde in medium for $10 \mathrm{~min}$ at $37^{\circ} \mathrm{C}$. The reaction was stopped by addition of $0.125 \mathrm{M}$ glycine, and the sample was incubated for $5 \mathrm{~min}$ at room temperature. Cells were then washed twice in cold PBS and pelleted. The pellet was resuspended in RIPA buffer $(50 \mathrm{mM}$ Tris at $\mathrm{pH} 7.4,150 \mathrm{mM} \mathrm{NaCl}$, $1 \mathrm{mM}$ EDTA, $0.1 \%$ SDS, $1 \%$ NP-40, $0.5 \%$ sodium deoxycholate, $0.5 \mathrm{mM}$ DTT, $1 \mathrm{mM}$ PMSF/cocktail, $500 \mathrm{U} / \mathrm{mL}$ RNasin), incubated for $30 \mathrm{~min}$ on ice, and then sonicated, and the lysate was obtained by centrifugation at 13,000 rpm for $10 \mathrm{~min}$. Antibodies were added, and samples were incubated for $16 \mathrm{~h}$ at $4^{\circ} \mathrm{C}$. Samples were washed twice in RIPA buffer supplemented with RNasin, four times in $1 \mathrm{M}$ RIPA buffer $(50 \mathrm{mM}$ Tris at $\mathrm{pH} 7.4,1 \mathrm{M} \mathrm{NaCl}$, $1 \mathrm{mM}$ EDTA, $0.1 \%$ SDS, $1 \%$ NP-40, RNasin $500 \mathrm{U} / \mathrm{mL}, 0.5 \%$ sodium deoxycholate), and then twice in RIPA. The beads were resuspended in RIPA buffer and treated with proteinase K. RNA samples were first extracted with Trizol and then with 1 vol of chloroform. Precipitated RNAs were treated with $40 \mathrm{U} / \mathrm{mL}$ DNase I (RNase-free, Ambion) followed by acid phenol extraction, precipitated, and detected by quantitative RT-PCR. NonRT controls (without reverse transcriptase) were performed simultaneously to demonstrate that the signals were not from DNA contamination.

\section{Immunofluorescence assays}

T47D-MTVL, T47D-MTVL-FlagH3wt, and T47D-MTVLFlagH3S10A cells were cultured onto coverslips in six-well multidishes and treated or not with RNase or transfected with siRNA as described above. After treatments, cells were washed and fixed by incubation in $4 \%$ paraformaldehyde in $0.1 \%$ TweenPBS for $15 \mathrm{~min}$ at room temperature and permeabilized by incubation in $0.2 \%$ Triton X-100 for $15 \mathrm{~min}$ at room temperature. After rinsing three times for $5 \mathrm{~min}$ in $1 \times$ PBS, the coverslips were 
incubated for $1 \mathrm{~h}$ with $10 \%$ BSA in $0.05 \%$ Triton X-100-PBS to reduce nonspecific staining. After one wash with PBS, coverslips were incubated with anti-HP1 $\gamma(1: 1000$; Euromedex), antiH3K9me3 (1:1000; Abcam), or anti-Flag (Sigma-Aldrich, M2) antibodies for $1 \mathrm{~h}$ at room temperature. After several washes in PBS, coverslips were exposed to secondary antibody for $1 \mathrm{~h}$ at room temperature. Coverslips were mounted on slides, and fluorescence images were registered with a confocal laser microscopy system (Leica TCS SP5) with a HCX PL APO $63 \times / 1.32$ oil CS objective.

\section{Solexa ChIP-seq analysis}

DNA was subjected to deep sequencing using the Solexa genome analyzer (Illumina). Single-ended sequences were trimmed to $50 \mathrm{bp}$ and mapped to the human genome assembly hg19 using Bowtie (http//bowtie-bio.sourceforge.net), an ultrafast short-read mapping program (Langmead et al. 2009), keeping only tags that mapped uniquely and with no more than two mismatches.

\section{Peak detection and annotation analysis}

The integrated software Macs (Zhang et al. 2008) was used to detect peaks that were enriched from background reads. The algorithm was applied by using the sliding window method to count the reads using the "nomodel" option, shift size set to 75, tag size set to 50 , and a $P$-value threshold of $1 \times 10^{-3}$ settings for HP1 $\gamma$ and LSD1 and to identify differential binding between the two conditions by treating the T0 of the samples as the control. In the case of $\mathrm{H} 3 \mathrm{~K} 9 \mathrm{me} 3$, the algorithm was applied using "nomodel," "nolambda," and a $P$-value threshold of $1 \times$ $10^{-3}$. In order to perform the average profiles, we used $\mathrm{R}$ programming language for plotting the mapped read signals over the regions of interest. All of the genome-wide annotations and statistics of protein-DNA interaction patterns from ChIP-seq data were performed with the standalone application CEAS (Cis-regulatory Element Annotation System). In the case of the ChiP-seq PR data, the signals of treated and untreated samples were compared using Poisson analysis $(P$-value $<0.001)$ (Ballare et al. 2013).

\section{Cell proliferation assay}

T47DMTVL cells transfected with control or SRA siRNAs were cultured as described above. Cells $\left(1 \times 10^{4}\right)$ were plated in a 96-well plate in the presence or absence of $10 \mathrm{nM}$ R5020. The cell proliferation ELISA BrdU Colorimetric assay (Roche) was performed according to the manufacturer's instructions. Figure 6F shows the percentage increase of proliferation in the presence versus absence of R5020. The experiments were performed in quintuplicate.

\section{Acknowledgments}

We thank Juan Valcárcel and Luciano Di Croce for advice on the manuscript. The experimental work was supported by grants from the Departament d'Innovació Universitat i Empresa (DIUiE), Ministerio de Educación y Ciencia (MEC) (BFU2010-01531 and BFU2011-28587), Consolider (CSD2006-00049), and Fondo de Investigación Sanitaria (FIS) PI0411605. G.P.V. is a recipient of the I3 Program.

\section{References}

Akhtar A, Zink D, Becker PB. 2000. Chromodomains are proteinRNA interaction modules. Nature 407: 405-409.
Archer TK, Lefebvre P, Wolford RG, Hager GL. 1992. Transcription factor loading on the MMTV promoter: A bimodal mechanism for promoter activation. Science 255: 1573-1576.

Ayoub N, Jeyasekharan AD, Bernal JA, Venkitaraman AR. 2008. HP1- $\beta$ mobilization promotes chromatin changes that initiate the DNA damage response. Nature 453: 682-686.

Ballare C, Castellano G, Gaveglia L, Althammer S, GonzalezVallinas J, Eyras E, Le Dily F, Zaurin R, Soronellas D, Vicent GP, et al. 2013. Nucleosome-driven transcription factor binding and gene regulation. Mol Cell 49: 67-79.

Bannister AJ, Kouzarides T. 2011. Regulation of chromatin by histone modifications. Cell Res 21: 381-395.

Bannister AJ, Zegerman P, Partridge JF, Miska EA, Thomas JO, Allshire RC, Kouzarides T. 2001. Selective recognition of methylated lysine 9 on histone H3 by the HP1 chromo domain. Nature 410: 120-124.

Barrett A, Madsen B, Copier J, Lu PJ, Cooper L, Scibetta AG, Burchell J, Taylor-Papadimitriou J. 2002. PLU-1 nuclear protein, which is upregulated in breast cancer, shows restricted expression in normal human adult tissues: A new cancer/ testis antigen? Int J Cancer 101: 581-588.

Beato M, Vicent GP. 2011. When every minute counts: The enzymatic complexity associated with the activation of hormone-dependent genes. Cell Cycle 10: 2407-2409.

Beato M, Vicent GP. 2012. Impact of chromatin structure and dynamics on PR signaling. The initial steps in hormonal gene regulation. Mol Cell Endocrinol 357: 37-42.

Bruggemeier U, Rogge L, Winnacker EL, Beato M. 1990. Nuclear factor I acts as a transcription factor on the MMTV promoter but competes with steroid hormone receptors for DNA binding. EMBO J 9: 2233-2239.

Chalepakis G, Arnemann J, Slater E, Bruller HJ, Gross B, Beato M. 1988. Differential gene activation by glucocorticoids and progestins through the hormone regulatory element of mouse mammary tumor virus. Cell 53: 371-382.

Colley SM, Leedman PJ. 2009. SRA and its binding partners: An expanding role for RNA-binding coregulators in nuclear receptor-mediated gene regulation. Crit Rev Biochem Mol Biol 44: 25-33.

Colley SM, Leedman PJ. 2011. Steroid receptor RNA activator A nuclear receptor coregulator with multiple partners: Insights and challenges. Biochimie 93: 1966-1972.

Daujat S, Zeissler U, Waldmann T, Happel N, Schneider R. 2005. HP1 binds specifically to Lys26-methylated histone H1.4, whereas simultaneous Ser27 phosphorylation blocks HP1 binding. I Biol Chem 280: 38090-38095.

Eissenberg JC, Shilatifard A. 2006. Leaving a mark: The many footprints of the elongating RNA polymerase II. Curr Opin Genet Dev 16: 184-190.

Emberley E, Huang GJ, Hamedani MK, Czosnek A, Ali D, Grolla A, Lu B, Watson PH, Murphy LC, Leygue E. 2003. Identification of new human coding steroid receptor RNA activator isoforms. Biochem Biophys Res Commun 301: 509-515.

Fischle W, Tseng BS, Dormann HL, Ueberheide BM, Garcia BA, Shabanowitz J, Hunt DF, Funabiki H, Allis CD. 2005. Regulation of HP1-chromatin binding by histone $\mathrm{H} 3$ methylation and phosphorylation. Nature 438: 1116-1122.

Foulds CE, Tsimelzon A, Long W, Le A, Tsai SY, Tsai MJ, O'Malley BW. 2010. Research resource: Expression profiling reveals unexpected targets and functions of the human steroid receptor RNA activator (SRA) gene. Mol Endocrinol 24: 1090-1105.

Gupta RA, Shah N, Wang KC, Kim J, Horlings HM, Wong DJ, Tsai MC, Hung T, Argani P, Rinn JL, et al. 2010. Long noncoding RNA HOTAIR reprograms chromatin state to promote cancer metastasis. Nature 464: 1071-1076. 
Guttman M, Donaghey J, Carey BW, Garber M, Grenier JK, Munson G, Young G, Lucas AB, Ach R, Bruhn L, et al. 2011. lincRNAs act in the circuitry controlling pluripotency and differentiation. Nature 477: 295-300.

Hakimi MA, Bochar DA, Chenoweth J, Lane WS, Mandel G, Shiekhattar R. 2002. A core-BRAF35 complex containing histone deacetylase mediates repression of neuronal-specific genes. Proc Natl Acad Sci 99: 7420-7425.

Hatchell EC, Colley SM, Beveridge DJ, Epis MR, Stuart LM, Giles KM, Redfern AD, Miles LE, Barker A, MacDonald LM, et al. 2006. SLIRP, a small SRA binding protein, is a nuclear receptor corepressor. Mol Cell 22: 657-668.

Hiragami-Hamada K, Shinmyozu K, Hamada D, Tatsu Y, Uegaki K, Fujiwara S, Nakayama J. 2011. N-terminal phosphorylation of $\mathrm{HP} 1 \alpha$ promotes its chromatin binding. Mol Cell Biol 31: 1186-1200.

Horwitz KB, Tung L, Takimoto GS. 1995. Novel mechanisms of antiprogestin action. I Steroid Biochem Mol Biol 53: 9-17.

Huarte M, Guttman M, Feldser D, Garber M, Koziol MJ Kenzelmann-Broz D, Khalil AM, Zuk O, Amit I, Rabani M, et al. 2010. A large intergenic noncoding RNA induced by p53 mediates global gene repression in the p53 response. Cell 142: 409-419.

Hube F, Velasco G, Rollin J, Furling D, Francastel C. 2011. Steroid receptor RNA activator protein binds to and counteracts SRA RNA-mediated activation of MyoD and muscle differentiation. Nucleic Acids Res 39: 513-525.

Hynes N, van Ooyen AJ, Kennedy N, Herrlich P, Ponta H, Groner B. 1983. Subfragments of the large terminal repeat cause glucocorticoid-responsive expression of mouse mammary tumor virus and of an adjacent gene. Proc Natl Acad Sci 80: 3637-3641.

Jacobs SA, Taverna SD, Zhang Y, Briggs SD, Li J, Eissenberg JC, Allis CD, Khorasanizadeh S. 2001. Specificity of the HP1 chromo domain for the methylated $\mathrm{N}$-terminus of histone H3. EMBO I 20: 5232-5241.

Jenuwein T, Allis CD. 2001. Translating the histone code. Science 293: 1074-1080.

Kino T, Hurt DE, Ichijo T, Nader N, Chrousos GP. 2010. Noncoding RNA gas5 is a growth arrest- and starvation-associated repressor of the glucocorticoid receptor. Sci Signal 3: ra8.

Kirschmann DA, Lininger RA, Gardner LM, Seftor EA, Odero VA, Ainsztein AM, Earnshaw WC, Wallrath LL, Hendrix MJ. 2000. Down-regulation of HP1Hs $\alpha$ expression is associated with the metastatic phenotype in breast cancer. Cancer Res 60: 3359-3363.

Ko MS, Nakauchi H, Takahashi N. 1990. The dose dependence of glucocorticoid-inducible gene expression results from changes in the number of transcriptionally active templates. EMBO I 9: 2835-2842.

Kouzarides T. 2007. Chromatin modifications and their function. Cell 128: 693-705.

Krishnakumar R, Kraus WL. 2010. PARP-1 regulates chromatin structure and transcription through a KDM5B-dependent pathway. Mol Cell 39: 736-749.

Kurokawa R. 2011. Long noncoding RNA as a regulator for transcription. Prog Mol Subcell Biol 51: 29-41.

Lachner M, O'Carroll D, Rea S, Mechtler K, Jenuwein T. 2001. Methylation of histone $\mathrm{H} 3$ lysine 9 creates a binding site for HP1 proteins. Nature 410: 116-120.

Langmead B, Trapnell C, Pop M, Salzberg SL. 2009. Ultrafast and memory-efficient alignment of short DNA sequences to the human genome. Genome Biol 10: R25.

Lanz RB, McKenna NJ, Onate SA, Albrecht U, Wong I, Tsai SY, Tsai MJ, O'Malley BW. 1999. A steroid receptor coactivator,
SRA, functions as an RNA and is present in an SRC-1 complex. Cell 97: 17-27.

Lee MG, Wynder C, Bochar DA, Hakimi MA, Cooch N, Shiekhattar R. 2006. Functional interplay between histone demethylase and deacetylase enzymes. Mol Cell Biol 26: 6395-6402.

Lee SW, Cho YS, Na JM, Park UH, Kang M, Kim EJ, Um SJ. 2010. ASXL1 represses retinoic acid receptor-mediated transcription through associating with HP1 and LSD1. I Biol Chem 285: $18-29$.

Leygue E. 2007. Steroid receptor RNA activator (SRA1): Unusual bifaceted gene products with suspected relevance to breast cancer. Nucl Recept Signal 5: e006.

Lim S, Janzer A, Becker A, Zimmer A, Schule R, Buettner R, Kirfel J. 2010. Lysine-specific demethylase 1 (LSD1) is highly expressed in ER-negative breast cancers and a biomarker predicting aggressive biology. Carcinogenesis 31: 512-520.

Liu J, Xiao N, DeFranco DB. 1999. Use of digitonin-permeabilized cells in studies of steroid receptor subnuclear trafficking. Methods 19: 403-409.

Lomberk G, Bensi D, Fernandez-Zapico ME, Urrutia R. 2006. Evidence for the existence of an HP1-mediated subcode within the histone code. Nat Cell Biol 8: 407-415.

Lonard DM, O'Malley BW. 2007. Nuclear receptor coregulators: Judges, juries, and executioners of cellular regulation. Mol Cell 27: 691-700.

Lu PJ, Sundquist K, Baeckstrom D, Poulsom R, Hanby A, MeierEwert S, Jones T, Mitchell M, Pitha-Rowe P, Freemont $\mathrm{P}$, et al. 1999. A novel gene (PLU-1) containing highly conserved putative DNA/chromatin binding motifs is specifically upregulated in breast cancer. I Biol Chem 274: 15633-15645.

Lu BY, Emtage PC, Duyf BJ, Hilliker AJ, Eissenberg JC. 2000. Heterochromatin protein 1 is required for the normal expression of two heterochromatin genes in Drosophila. Genetics 155: 699-708

Luger K, Mader AW, Richmond RK, Sargent DF, Richmond TJ. 1997. Crystal structure of the nucleosome core particle at 2.8 A resolution. Nature 389: 251-260.

Maison C, Bailly D, Peters AH, Quivy JP, Roche D, Taddei A, Lachner M, Jenuwein T, Almouzni G. 2002. Higher-order structure in pericentric heterochromatin involves a distinct pattern of histone modification and an RNA component. Nat Genet 30: 329-334.

Mariner PD, Walters RD, Espinoza CA, Drullinger LF, Wagner SD, Kugel JF, Goodrich JA. 2008. Human Alu RNA is a modular transacting repressor of mRNA transcription during heat shock. Mol Cell 29: 499-509.

Mateescu B, England P, Halgand F, Yaniv M, Muchardt C. 2004. Tethering of HP1 proteins to chromatin is relieved by phosphoacetylation of histone H3. EMBO Rep 5: 490-496.

Metzger E, Wissmann M, Yin N, Muller JM, Schneider R, Peters AH, Gunther T, Buettner R, Schule R. 2005. LSD1 demethylates repressive histone marks to promote androgen-receptordependent transcription. Nature 437: 436-439.

Migliaccio A, Piccolo D, Castoria G, Di Domenico M, Bilancio A, Lombardi M, Gong W, Beato M, Auricchio F. 1998. Activation of the Src/p21ras/Erk pathway by progesterone receptor via cross-talk with estrogen receptor. EMBO J 17: 2008-2018.

Muchardt C, Guilleme M, Seeler JS, Trouche D, Dejean A, Yaniv M. 2002. Coordinated methyl and RNA binding is required for heterochromatin localization of mammalian HP1 $\alpha$. EMBO Rep 3: 975-981.

Nielsen PR, Nietlispach D, Mott HR, Callaghan J, Bannister A, Kouzarides T, Murzin AG, Murzina NV, Laue ED. 2002. Structure of the HP1 chromodomain bound to histone H3 methylated at lysine 9. Nature 416: 103-107. 
Niranjanakumari S, Lasda E, Brazas R, Garcia-Blanco MA. 2002. Reversible cross-linking combined with immunoprecipitation to study RNA-protein interactions in vivo. Methods 26: 182-190.

Ooi L, Wood IC. 2007. Chromatin crosstalk in development and disease: Lessons from REST. Nat Rev Genet 8: 544-554.

Payvar F, DeFranco D, Firestone GL, Edgar B, Wrange O, Okret S, Gustafsson JA, Yamamoto KR. 1983. Sequence-specific binding of glucocorticoid receptor to MTV DNA at sites within and upstream of the transcribed region. Cell 35: 381-392.

Peters AH, O'Carroll D, Scherthan H, Mechtler K, Sauer S, Schofer C, Weipoltshammer K, Pagani M, Lachner M, Kohlmaier A, et al. 2001. Loss of the Suv39h histone methyltransferases impairs mammalian heterochromatin and genome stability. Cell 107: 323-337.

Richard-Foy H, Hager GL. 1987. Sequence-specific positioning of nucleosomes over the steroid-inducible MMTV promoter. EMBO J 6: 2321-2328.

Sachs LM, Jones PL, Havis E, Rouse N, Demeneix BA, Shi YB. 2002. Nuclear receptor corepressor recruitment by unliganded thyroid hormone receptor in gene repression during Xenopus laevis development. Mol Cell Biol 22: 8527-8538.

Scheidereit C, Geisse S, Westphal HM, Beato M. 1983. The glucocorticoid receptor binds to defined nucleotide sequences near the promoter of mouse mammary tumour virus. Nature 304: 749-752.

Shi Y, Lan F, Matson C, Mulligan P, Whetstine JR, Cole PA, Casero RA. 2004. Histone demethylation mediated by the nuclear amine oxidase homolog LSD1. Cell 119: 941-953.

Shi YJ, Matson C, Lan F, Iwase S, Baba T, Shi Y. 2005. Regulation of LSD1 histone demethylase activity by its associated factors. Mol Cell 19: 857-864.

Strutt H, Paro R. 1999. Mapping DNA target sites of chromatin proteins in vivo by formaldehyde crosslinking. Methods Mol Biol 119: 455-467.

Thornton JW, Need E, Crews D. 2003. Resurrecting the ancestral steroid receptor: Ancient origin of estrogen signaling. Science 301: 1714-1717.

Truss M, Bartsch J, Schelbert A, Hache RJ, Beato M. 1995. Hormone induces binding of receptors and transcription factors to a rearranged nucleosome on the MMTV promoter in vivo. EMBO J 14: 1737-1751.

Tsai MC, Manor O, Wan Y, Mosammaparast N, Wang JK, Lan F, Shi Y, Segal E, Chang HY. 2010. Long noncoding RNA as modular scaffold of histone modification complexes. Science 329: 689-693.

Vicent GP, Ballare C, Nacht AS, Clausell J, Subtil-Rodriguez A, Quiles I, Jordan A, Beato M. 2006. Induction of progesterone target genes requires activation of Erk and Msk kinases and phosphorylation of histone H3. Mol Cell 24: 367-381.

Vicent GP, Zaurin R, Nacht AS, Li A, Font-Mateu J, Le Dily F, Vermeulen M, Mann M, Beato M. 2009. Two chromatin remodeling activities cooperate during activation of hormone responsive promoters. PLoS Genet 5: e1000567.

Vicent GP, Nacht AS, Font-Mateu J, Castellano G, Gaveglia L, Ballare C, Beato M. 2011. Four enzymes cooperate to displace histone $\mathrm{H} 1$ during the first minute of hormonal gene activation. Genes Dev 25: 845-862.

Wang KC, Chang HY. 2011. Molecular mechanisms of long noncoding RNAs. Mol Cell 43: 904-914.

Wang J, Scully K, Zhu X, Cai L, Zhang J, Prefontaine GG, Krones A, Ohgi KA, Zhu P, Garcia-Bassets I, et al. 2007. Opposing LSD1 complexes function in developmental gene activation and repression programmes. Nature 446: 882-887.

Wang Q, Li W, Zhang Y, Yuan X, Xu K, Yu J, Chen Z, Beroukhim R, Wang H, Lupien M, et al. 2009. Androgen receptor regulates a distinct transcription program in androgen-independent prostate cancer. Cell 138: 245-256.

Weston AD, Blumberg B, Underhill TM. 2003. Active repression by unliganded retinoid receptors in development: Less is sometimes more. J Cell Biol 161: 223-228.

Wright RH, Castellano G, Bonet J, Le Dily F, Font-Mateu J, Ballare C, Nacht AS, Soronellas D, Oliva B, Beato M. 2012. CDK2-dependent activation of PARP-1 is required for hormonal gene regulation in breast cancer cells. Genes Dev 26: 1972-1983.

Yamane K, Tateishi K, Klose RJ, Fang J, Fabrizio LA, ErdjumentBromage H, Taylor-Papadimitriou I, Tempst P, Zhang Y. 2007. PLU-1 is an H3K4 demethylase involved in transcriptional repression and breast cancer cell proliferation. Mol Cell 25: 801-812.

Yao H, Brick K, Evrard Y, Xiao T, Camerini-Otero RD, Felsenfeld G. 2010. Mediation of CTCF transcriptional insulation by DEAD-box RNA-binding protein p68 and steroid receptor RNA activator SRA. Genes Dev 24: 2543-2555.

Zhang Y, Liu T, Meyer CA, Eeckhoute J, Johnson DS, Bernstein BE, Nusbaum C, Myers RM, Brown M, Li W, et al. 2008. Model-based analysis of ChIP-seq (MACS). Genome Biol 9: R137.

Zheng ZY, Zheng SM, Bay BH, Aw SE, C-L Lin, V. 2008. Antiestrogenic mechanism of unliganded progesterone receptor isoform B in breast cancer cells. Breast Cancer Res Treat 110: 111-125.

Zwicker J, Lucibello FC, Jerome V, Brusselbach S, Muller R. 1998. CDF-1 mediated repression of cell cycle genes targets a specific subset of transactivators. Nucleic Acids Res 26: 4926-4932. 


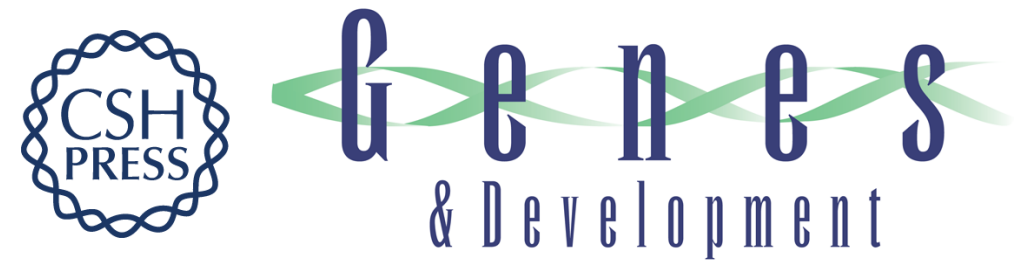

\section{Unliganded progesterone receptor-mediated targeting of an RNA-containing repressive complex silences a subset of hormone-inducible genes}

Guillermo Pablo Vicent, A. Silvina Nacht, Roser Zaurin, et al.

Genes Dev. 2013, 27:

Access the most recent version at doi:10.1101/gad.215293.113

Supplemental
Material http://genesdev.cshlp.org/content/suppl/2013/05/22/27.10.1179.DC1

Related Content Repress, Derepress, Activate

Annalisa M. VanHook

Sci. Signal. June , 2013 6: ec128

References This article cites 81 articles, 22 of which can be accessed free at:

http://genesdev.cshlp.org/content/27/10/1179.full.html\#ref-list-1

Articles cited in:

http://genesdev.cshlp.org/content/27/10/1179.full.html\#related-urls

License

Email Alerting Receive free email alerts when new articles cite this article - sign up in the box at the top Service right corner of the article or click here.

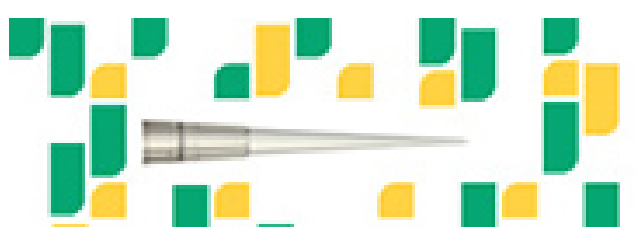

Focused on your science. 